\title{
๖Microphysics Impacts on the Warm Conveyor Belt and Ridge Building of the NAWDEX IOP6 Cyclone
}

\author{
Marie Mazoyer, ${ }^{\mathrm{a}}$ Didier Ricard, ${ }^{\mathrm{a}}$ Gwendal Rivière, ${ }^{\mathrm{b}}$ Julien Delanoë, ${ }^{\mathrm{c}}$ PhilipPe Arbogast, ${ }^{\mathrm{a}}$ \\ Benoit Vié, ${ }^{\mathrm{a}}$ Christine Lac, ${ }^{\mathrm{a}}$ QuitTerie CAZenave, ${ }^{\mathrm{c}}$ AND Jacques Pelon ${ }^{\mathrm{c}}$ \\ ${ }^{\text {a }}$ CNRM, Université de Toulouse, Météo-France, CNRS, Toulouse, France \\ ${ }^{\mathrm{b}}$ LMD/IPSL, École Normale Supérieure, PSL Research University, École Polytechnique, Sorbonne \\ Universités, CNRS, Paris, France \\ ${ }^{\mathrm{c}}$ LATMOS-IPSL, CNRS/INSU, University of Versailles, Guyancourt, France
}

(Manuscript received 25 March 2021, in final form 3 September 2021)

\begin{abstract}
This study investigates diabatic processes along the warm conveyor belt (WCB) of a deep extratropical cyclone observed in the North Atlantic Waveguide and Downstream Impact Experiment (NAWDEX). The aim is to investigate the effect of two different microphysics schemes, the one-moment scheme ICE3 and the quasi two-moment scheme LIMA, on the WCB and the ridge building downstream. ICE3 and LIMA also differ in the processes of vapor deposition on hydrometeors in cold and mixed-phase clouds. Latent heating in ICE3 is found to be dominated by deposition on ice while the heating in LIMA is distributed among depositions on ice, snow, and graupel. ICE3 is the scheme leading to the largest number of WCB trajectories ( $30 \%$ more than LIMA) due to greater heating rates over larger areas. The consequence is that the size of the upper-level ridge grows more rapidly in ICE3 than LIMA, albeit with some exceptions in localized regions of the cyclonic branch of the WCB. A comparison with various observations (airborne remote sensing measurements, dropsondes, and satellite data) is then performed. Below the melting layer, the observed reflectivity is rather well reproduced by the model. Above the melting layer, in the middle of the troposphere, the reflectivity and retrieved ice water content are largely underestimated by both schemes while at upper levels, the ICE3 scheme performs much better than LIMA in agreement with a closer representation of the observed winds by ICE3. These results underline the strong sensitivity of upper-level dynamics to ice-related processes.
\end{abstract}

SIGNIFICANCE STATEMENT: In midlatitudes, the jet stream structure is modulated by diabatic processes occurring in the warm conveyor belt of extratropical cyclones. By using two drastically different microphysical schemes to simulate an extratropical cyclone, we investigate the main cloud processes and associated uncertainties mattering to represent the warm conveyor belt. Comparison with data from the NAWDEX campaign helps to determine the most accurate scheme. We highlight the strong sensitivity of upper-level dynamics to ice-related processes. These findings point out the need of a better understanding of these processes for an improved prediction of upper-level dynamics.

KEYWORDS: Extratropical cyclones; Cloud microphysics; Diabatic heating

\section{Introduction}

Extratropical cyclones result from complex interactions between synoptic-scale dynamical forcings and microscale physical processes and are still subject to significant prediction errors in numerical weather prediction models (NWP). Warm conveyor belts (WCB) are key regions of extratropical cyclones where these multiscale complex interactions occur. According to Eckhardt et al. (2004), in the Northern Hemisphere, $~ 60 \%$ of the extratropical cyclones are associated with WCB and their deepening rate is linked to the WCB strength (Binder et al. 2016). WCBs correspond to slantwise ascending air masses originating in the boundary layer of the warm sector and reaching the upper troposphere (Harrold 1973; Browning 1986). Within the

\footnotetext{
D Denotes content that is immediately available upon publication as open access.
}

Corresponding author: Marie Mazoyer, marie.mazoyer@ meteo.fr troposphere, they form elongated cloud bands and horizontally transport large amounts of heat and moisture (Holton 2004). During their ascent, liquid, mixed phase, and ice hydrometeors are formed in WCBs (Browning 1986).

Microphysical water phase changes associated with cloud formation along WCBs have been shown to have a strong impact on cyclone intensity (Manabe 1956; Robertson and Smith 1983, among many others) and cyclone track (Coronel et al. 2015). These impacts can be viewed in terms of potential vorticity (PV). The time evolution of the PV depends on the spatial gradient of the diabatic heating rate (Hoskins et al. 1985). In WCBs, microphysical processes generally produce latent heat release larger than $20 \mathrm{~K}$ in $48 \mathrm{~h}$ (Madonna et al. 2014). Such a latent heat release produces a positive PV anomaly in the lower troposphere which generally reinforces the cyclonic circulation of the surface extratropical cyclones (Kuo et al. 1991; Davis et al. 1993; Binder et al. 2016). The latent heat release also creates a negative PV anomaly in the upper troposphere that tends to reinforce the downstream ridge (Hoskins et al. 1985; Wernli and Davies 1997; Pomroy and Thorpe 2000; Madonna et al. 2014). This upper tropospheric PV anomaly has a 
strong impact on the downstream propagation of Rossby waves and consequently on the forthcoming weather. Several studies have shown that NWP models are often characterized by a misrepresentation of the PV along the jet stream (Dirren et al. 2003; Gray et al. 2014; Martínez-Alvarado et al. 2016) whose origins might be diabatic processes, and in particular the cloud microphysical processes within WCBs. These previous studies helped motivate the international field campaign, the North Atlantic Waveguide Downstream and Impact Experiment (NAWDEX), which was conducted in September-October 2016 (Schäfler et al. 2018).

The most significant microphysical processes along WCBs are associated with condensation of cloud liquid water, depositional growth of snow and ice, and snow riming as shown by various studies (Forbes and Clark 2003; Joos and Wernli 2012; Joos and Forbes 2016; Dearden et al. 2016; Crezee et al. 2017; Gehring et al. 2020). Cloud systems have been shown to be highly dependent on the way ice vapor growth is parameterized (Gierens et al. 2003; Tompkins et al. 2007; Avramov and Harrington 2010) but uncertainties on ice related processes are still large (Khain et al. 2015; Dearden et al. 2016). In warm clouds, all the excess vapor is removed by a saturation adjustment scheme. In cold and mixed clouds, saturation adjustment is also often used. However, ice number concentration is several orders smaller than cloud droplets number concentration and supersaturation reached in cold and mixed clouds is far higher than in warm clouds and the assumption of saturation adjustment is no longer applicable (Heymsfield et al. 1998; Gettelman et al. 2010). When the ice-saturation adjustment is applied, the excess water vapor in the upper troposphere is entirely consumed to produce large amount of cloud ice and subsequently releases large amount of latent heating (Hashimoto et al. 2007). By doubling or halving the ice deposition rate in a mesoscale version of the Met Office Unified Model, Forbes and Clark (2003) observed significant impacts on the dynamics of a cyclone and its fronts but, due to the absence of microphysics observations, the authors could not state on the best deposition rate and they did not look at the representation of the PV along the jet stream. Joos and Forbes (2016), while using different microphysics differing on accretion, rain evaporation and snow riming, detected small changes in the structure and location of the WCB that have some impact on the position of the tropopause and extension of the upper-level ridge. However, these differences in microphysics did not lead to differences in the number of WCB trajectories. Extratropical cyclones are complex systems and the underlying interactions between microphysics and dynamics within WCB may potentially lead to forecast uncertainties along the downstream waveguide (Berman and Torn 2019). However, it is still unclear to which components of the microphysical schemes along WCB trajectories the downstream waveguide is more sensitive.

The main objective of the present study is to assess the impact of different microphysics on the development of an extratropical cyclone and its associated ridge building aloft in the French mesoscale research model MésoNH (Lac et al. 2018). Two largely different microphysics schemes are compared: the one-moment microphysical scheme ICE3 (Pinty and Jabouille 1998) and the quasi two-moment microphysical scheme, the Liquid Ice Multiple Aerosols (LIMA; Vié et al. (2016)). Since the cyclone has been observed during the intensive observing period 6 (IOP6) of NAWDEX, a subsequent secondary objective is to determine which of the scheme performs better with regard to observations.

The one-moment scheme ICE3 is currently used in AROME (Seity et al. 2011), the operational regional NWP model at Météo-France. It describes the evolution of the mass mixing ratio of five different hydrometeors (droplets, rain, graupel, snow and ice). The quasi two-moment scheme LIMA describes the evolution of both the mass mixing ratios and number concentrations of the same five hydrometeors. These schemes also differ on the processes of vapor deposition on ice hydrometeors in cold and mixed clouds. For instance, ICE3 uses ice-saturation adjustment while LIMA predicts explicit rates of water vapor deposition.

Such a comparison between the two schemes has already been performed in a very different context on two heavy precipitation events of the HyMeX campaign (Ducrocq et al. 2014) by Taufour et al. (2018). The one-moment scheme produced higher values of hydrometeor mass mixing ratio. This could be due to, inter alia, higher vapor deposition rates or to lower sedimentation speeds. But the two-moment scheme obtained a closer vertical composition of the convective cells to the observations. This last point might be relevant in our case as Rasp et al. (2016), Oertel et al. (2021), and Blanchard et al. (2020) recently showed the particular roles of embedded convection in creating upper-level negative PV bands on the anticyclonic side of the jet stream and reinforcing it.

The case studied in this paper is called the "stalactite cyclone" due to a very deep, narrow, stalactite-like tropopause trough associated with it following the analogy introduced by Rossa et al. (2000). This case is particularly interesting to study because its associated ridge building led to the onset of a synoptic-scale Scandinavian blocking in early October 2016 (Schäfler et al. 2018; Maddison et al. 2019). It has been observed during three aircraft flights: two flights of the French Falcon operated by Service des Avions Français Instrumentés pour la Recherche en Environnement (SAFIRE) and one flight of the German Falcon operated by the Deutsches Zentrum für Luft- und Raumfahrt (DLR).

The structure of the paper is as follows. Section 2 is dedicated to the description of the NAWDEX case study and the methodology. It first includes information about the model and its detailed bulk microphysical schemes ICE3 and LIMA. It also includes a synoptic overview of the NAWDEX case study and a description of the observational datasets. The impact of the two schemes on the WCB of the studied cyclone and the building of the upperlevel ridge are then described in section 3 . Section 4 is dedicated to the comparison to airborne in situ and radar-lidar observations of microphysics and dynamics in an attempt to assess the effect of the microphysical schemes on the skill of the NWP model in the case studied here. A discussion and conclusions are drawn in section 5.

\section{Case description and methodology}

\section{a. NAWDEX IOP6}

The "stalactite cyclone" that formed during IOP6 of NAWDEX is selected for our study and corresponds to the beginning of 
sequence B as depicted in Schäfler et al. (2018) (e.g., see their Fig. 6). The initial cyclogenesis occurred off the coast of Newfoundland by the merging of two small-scale vortices on 29 September 2016 (Flack et al. 2021). An interaction with a large-scale upper-level trough over the North Atlantic led to a rapid deepening of the surface cyclone by $26 \mathrm{hPa}$ in $24 \mathrm{~h}$. Figure 1 presents the track of the cyclone obtained with the global operational model ARPEGE analysis from 0000 UTC 1 October to 0000 UTC 4 October every $6 \mathrm{~h}$ (black line in Fig. 1a). The cyclone was associated with a strong WCB that amplified the upper level ridge downstream of it (Figs. 1b-d). On 4 October the ridge led to a blocking situation that persisted over Scandinavia for several weeks (Schäfler et al. 2018; Maddison et al. 2019). Two flights with the French SAFIRE Falcon were conducted during the development of the cyclone and its associated WCB on 2 October (see flights tracks in Fig. 1b). The first one, called F6, lasted from 0837 to 1150 UTC and sampled the WCB outflow region west of Iceland. The second one, called F7, which lasted from 1301 to 1616 UTC, sampled the ascending branch of the WCB south of Iceland.

\section{b. French NAWDEX airborne observations and comparison with model outputs}

During NAWDEX, the French SAFIRE Falcon was equipped with a radar-lidar platform (RALI; http://rali.projet.latmos.ipsl.fr/, Delanoë et al. 2013). It includes a multibeam 95-GHz Doppler radar, Radar System Airborne (RASTA), a high-spectralresolution Leandre New Generation (LNG) lidar, and an infrared radiometer Conveyable Low-Noise Infrared Radiometer for Measurements of Atmosphere and Ground Surface Targets (CLIMAT; Brogniez et al. 2003). RASTA includes three downward-looking beams (nadir, $28^{\circ}$ off-nadir and opposite the aircraft motion, and $20^{\circ}$ off-nadir perpendicular to the aircraft motion). This unique configuration allows for the retrieval of the three-dimensional wind. LNG, in its backscatter configuration, operates at three wavelengths $(355,532$, and $1064 \mathrm{~nm})$, including depolarization at $355 \mathrm{~nm}$.

Two complementary approaches are adopted to compare the simulations and the observations: the radar-to-model approach, which consists of deriving usual meteorological parameters such as hydrometeor contents from radar-lidar measurements, and the model-to-radar approach, which simulates the reflectivity from the model fields. Both approaches have their own assumptions on hydrometeor shape, density, etc. The model-toradar approach relies on a radar forward operator developed within MésoNH following the Mie scattering theory. The simulated reflectivity can be compared to the reflectivity measured by a fixed ground-based radar (Caumont et al. 2006; Augros et al. 2016) or by one measured along a flight track (Borderies et al. 2018). The radar sensitivity depending on the range of the target (e.g., RASTA sensitivity is about $-30 \mathrm{dBZ}$ at $1-\mathrm{km}$ range) the radar cannot detect the very low values shown in the model simulations. Consequently, only the range of observed values are considered for comparison purposes. Therefore, at each altitude, the simulated reflectivity values that are smaller/larger than the minimum/maximum of the instrument range are excluded. In the latter study, the operator has been validated by comparisons with the RASTA data during a 2-month period over the Mediterranean region. The radar-to-model approach is based on the DARDAR-CLOUD algorithm (Delanoë et al. 2013; Cazenave 2019) which enables the retrieval of microphysical properties from the RALI data using T-matrix scattering theory (Mishchenko et al. 1996) such as the ice water content, the effective radius, and the extinction. Adopting these two complementary and independent approaches, which are based on different assumptions and exploitation algorithms, reinforces the robustness of our comparisons between observations and models and constitutes one originality of the present study.

Nine dropsondes were launched during F6 that provided temperature, humidity, and wind profiles. During F7, no dropsonde was launched because of the air traffic constraints. Finally, to get a fair comparison with the observations, MésoNH simulations are systematically interpolated in time and space at the exact position of the observations.

\section{c. Model and simulation setup}

This study uses the French anelastic research model MésoNH (Lac et al. 2018, http://mésonh.aero.obs-mip.fr/). The MésoNH prognostic variables are the three velocity components, the dry potential temperature, the turbulent kinetic energy and the microphysical variables. MésoNH was used in a convectionpermitting mode at a $2.5-\mathrm{km}$ horizontal resolution over the domain shown in Figs. 1a-d. The vertical grid included 55 stretched vertical levels with the first one $20 \mathrm{~m}$ above the ground. The momentum is advected with a fourth-order centered scheme, while scalar variables are advected with the piecewise parabolic method (PPM) scheme (Colella and Woodward 1984). The time step is $6 \mathrm{~s}$ with a Runge-Kutta fourth-order temporal scheme. The turbulence scheme is the 1D version of Cuxart et al. (2000) used with the mixing length of Bougeault and Lacarrere (1989) and the mass-flux scheme of Pergaud et al. (2009). The radiative transfer is computed with the ECMWF radiation code, using the Rapid Radiation Transfer Model (RRTM) of Mlawer et al. (1997) for longwave radiation and the shortwave radiation scheme of Morcrette (1991). In MésoNH backward Lagrangian trajectories are calculated using the online algorithm of Gheusi and Stein (2002). The tracers are initialized with their initial 3D coordinates and are transported by PPM, a scheme with excellent mass-conservation properties and low numerical diffusion. Two distinct simulations are performed in this study, the first uses the microphysical parameterization scheme ICE3 and the second LIMA. In what follows these simulations are referred to as ICE3 and LIMA simulations.

\section{1) ICE3 MICROPHYSICAL SCHEME}

ICE3 is a bulk mixed-phase one-moment microphysical scheme (Caniaux et al. 1994; Pinty and Jabouille 1998). Its prognostic equations predict the mass mixing ratios of six water species (water vapor, cloud water, rainwater, primary ice crystals, snow aggregates, and graupel) combining a three-class ice parameterization with the Kessler (1969) scheme applied to the warm processes. The total number concentration of the cloud droplets is defined according to the fraction of sea and land surface cover of the grid mesh, with $300 \times 10^{6} \mathrm{~m}^{-3}$ particles over land and $100 \times 10^{6} \mathrm{~m}^{-3}$ over sea. The total number 
a. Geop at $500 \mathrm{hPa}$ at 00 UTC 1 Oct

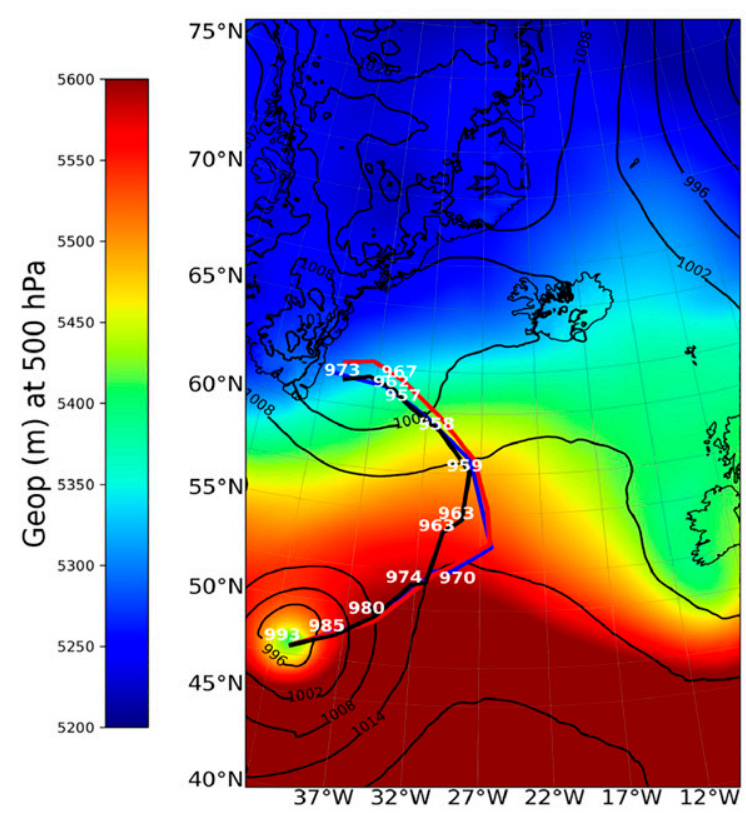

c. PV at $315 \mathrm{~K}$ at 00 UTC 2 Oct

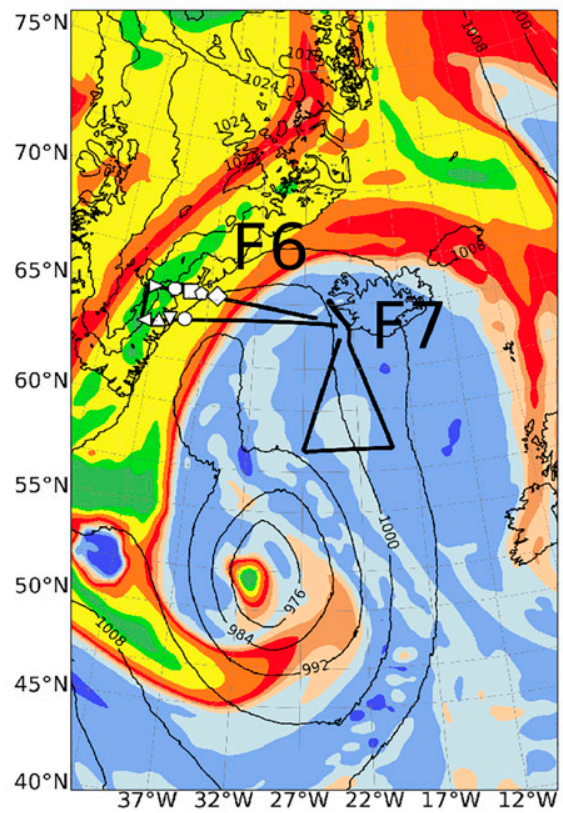

b. PV at $315 \mathrm{~K}$ at 00 UTC 1 Oct
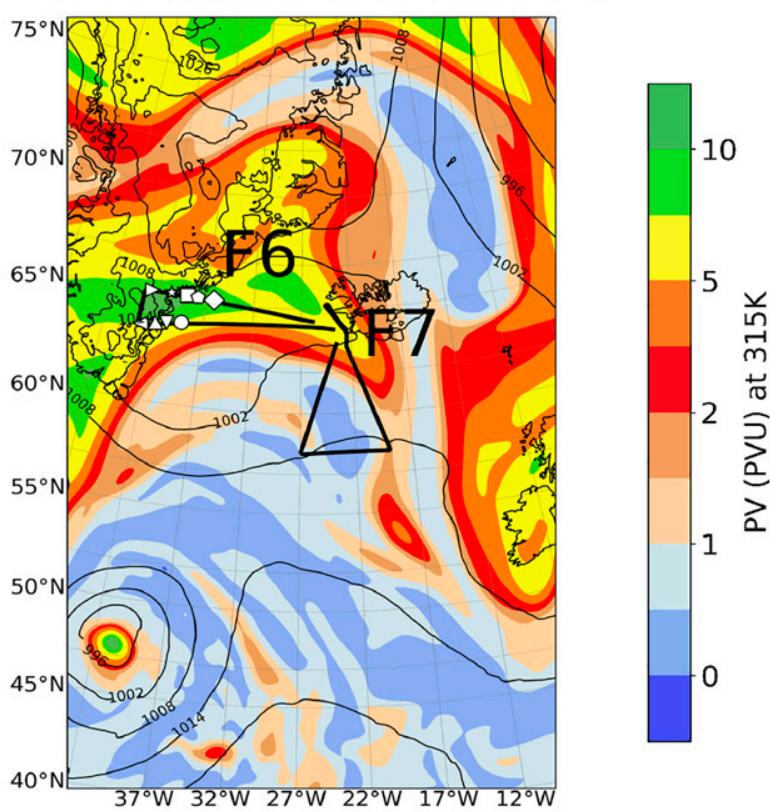

\section{d. PV at $315 \mathrm{~K}$ at 00 UTC 3 Oct}



FIG. 1. (a) Geopotential height at $500 \mathrm{hPa}$ from ARPEGE operational analysis at 0000 UTC 1 Oct. The black, blue, and red lines represent the 6-hourly evolution from 0000 UTC 1 Oct to 0000 UTC 4 Oct of the sea level pressure (SLP) minimum for the ARPEGE analysis, ICE3 run, and LIMA run, respectively. PV at the 315-K isentropic surface (shading; PVU) and SLP (black contours; interval: 8 hPa) for the ICE3 run at (b) 0000 UTC 1 Oct, (c) 0000 UTC 2 Oct, and (d) 0000 UTC 3 Oct. The flight tracks F6 and F7 are shown by the bold lines in (b)-(d). Symbols indicate the launch location for each dropsondes during flight F6.

concentration of the primary ice is diagnosed based on the parameterization of heterogeneous nucleation of Meyers et al. (1992), which depends only on the supersaturation. An adjustment to saturation for liquid/solid phase is performed meaning that there is deposition of the excess vapor on cloud droplets/ice particles in warm/cold clouds. In mixed-phase clouds, a barycentric formula based on ice and cloud droplets mass mixing ratio is used to divide the excess vapor between ice 
particles and cloud droplets, which may lead to artificial distribution between hydrometeors. Ice to snow conversion is performed according to Kessler (1969) and depends on the ice mass mixing ratio and on the temperature. In cold clouds, snow is only formed by autoconversion and aggregation of ice while graupel is first formed by riming and can then grow by collecting ice and snow. ICE3 includes a subgrid condensation scheme in which the cloud scheme considers saturation deficit according to Chaboureau and Bechtold (2002) and the shallow convection scheme of Pergaud et al. (2009).

\section{2) LIMA MICROPHYSICAL SCHEME}

LIMA (Vié et al. 2016) ${ }^{1}$ is a quasi-two-moment scheme that includes a detailed representation of aerosol-cloud interactions. LIMA inherits the six water species of the ICE3 scheme. In addition to the mass mixing ratio, and through aerosols consideration, it predicts the number concentration of the cloud droplets, raindrops and pristine ice crystals. As concentrations of snow and graupel are diagnostic, we use the term quasi two-moment scheme. The LIMA scheme integrates a prognostic representation of the aerosol population. cloud condensation nuclei $(\mathrm{CCN})$ activation is parameterized following Cohard et al. (1998). ice freezing nuclei (IFN) nucleation is parameterized according to Phillips et al. (2008) but revised as in Phillips et al. (2013). IFN nucleation explicitly depends on the surface properties of glaciogenic aerosols. In our simulations, the CCN number concentration is set to $300 \times$ $10^{6} \mathrm{~m}^{-3}$ between the ground and a height of $1000 \mathrm{~m}$. Above $1000 \mathrm{~m}$, the number concentration decreases exponentially up to $10000 \mathrm{~m}$ where it reaches a constant value of $10 \times 10^{3} \mathrm{~m}^{-3}$. The IFN number concentration is homogeneous and set to $10 \mathrm{~m}^{-3}$. Sensitivity tests to CCN and IFN number concentrations have been performed with very little impact on the simulations. As in ICE3, for the warm phase there is condensation of all the excess vapor on cloud liquid water. However, for the cold phase the deposition rate is explicitly predicted for ice, snow and graupel. In mixed-phase clouds, an adjustment to liquid water saturation first prevents supersaturation, and then the simultaneous evolution of droplets and ice crystals is parameterized after Reisin et al. (1996) and an explicit mass transfer rate on snow and graupel is computed.

In opposition to ICE3:

- No adjustment to saturation is made on solid phase and some vapor can stay in excess in the cold and mixed phases.

- Snow and graupel can grow by vapor deposition in the cold clouds.

- No subgrid condensation scheme is used.

These points are very relevant as, at each time step, mass is transferred between the six water species (vapor, ice, snow, graupel, rain and droplets) such that a change of phase occurs, and latent heat is released/consumed.

\footnotetext{
${ }^{1}$ Technical note on LIMA at http://mésonh.aero.obs-mip.fr/ mésonh54/BooksAndGuides? action $=$ AttachFile $\&$ do $=$ view $\&$ target $=$ scidoc_p3.pdf.
}

A previous comparison between these two schemes performed on heavy precipitation events Taufour et al. (2018) noticed several significant differences. LIMA was found to be more skillful in various ways: it produced a more realistic rain mass mixing ratio, a better representation of the hydrometeors contents as function of height, and an improvement of the representation of the hydrometeors contents in convective areas and the cloud tops. They also observed that LIMA produced more snow than ICE3 but less graupel and far less pristine ice (see their Fig. 8).

\section{3) INITIAL CONDITIONS, SYNOPTIC OVERVIEW, AND LAGRANGIAN TRAJECTORIES SEEDING}

The simulations are initialized at 0000 UTC 1 October 2016 and last $72 \mathrm{~h}$. Initial and lateral boundary conditions are provided by 6-hourly ARPEGE analyses. At the initial time the cyclone is located in the southwestern part of the MésoNH domain and the upper-level ridge to the east of the surface cyclone is partly formed and covers a large part of the MésoNH domain (Figs. 1a,b). The tracks of the cyclone, as simulated by ICE3 and LIMA, are almost superimposed on each other and slightly more to the east compared to ARPEGE analysis (Fig. 1a). At the end of the simulations, on 4 October, the surface low is not further deepening, while the ridge is amplifying farther to the north (not shown). The following results focus on the first 2 days of the simulations when the cyclone keeps deepening and the ridge amplifies the most.

Seeding of backward trajectories is made at 0000 UTC 3 October only when the differences between ICE3 and LIMA are already large enough. Information on trajectories is given every $15 \mathrm{~min}$ on a $2.5 \mathrm{~km} \times 2.5 \mathrm{~km}$ horizontal grid over the domain shown in Fig. 1. Due to the high computational cost, only one point over eight is considered in the horizontal directions. In the vertical direction all the 22 levels are seeded from 3600 to $14400 \mathrm{~m}$.

\section{Microphysics properties and latent heating budget along the warm conveyor belt}

Different criteria can be applied to identify WCB trajectories. This study follows Joos and Wernli (2012) and uses a criterion that requires an ascent of more than $600 \mathrm{hPa}$ in $48 \mathrm{~h}$. A significant difference in the number of WCB trajectories are found between the two runs: ICE3 has 10475 trajectories whereas LIMA 7945 trajectories. Figure 2 presents the WCB trajectories and their elevation during $48 \mathrm{~h}$. The ICE3 and LIMA trajectories and their ascending regions are very close to each other but are not the same. For some trajectories ascents from the lower to the upper troposphere occur in localized regions of few degrees extent in longitude and latitude (see e.g., $55^{\circ} \mathrm{N}, 32^{\circ} \mathrm{W}$ along the bent-back front) suggesting the possible occurrence of convective motion as in Rasp et al. (2016) or Oertel et al. (2019) for instance.

Figure 3a shows different rising speeds between ICE3 and LIMA WCB trajectories. LIMA WCB trajectories rise faster and slightly sooner than ICE3 WCB trajectories while having roughly the same starting and ending heights. When looking at the latitudinal and longitudinal evolutions (not shown), 

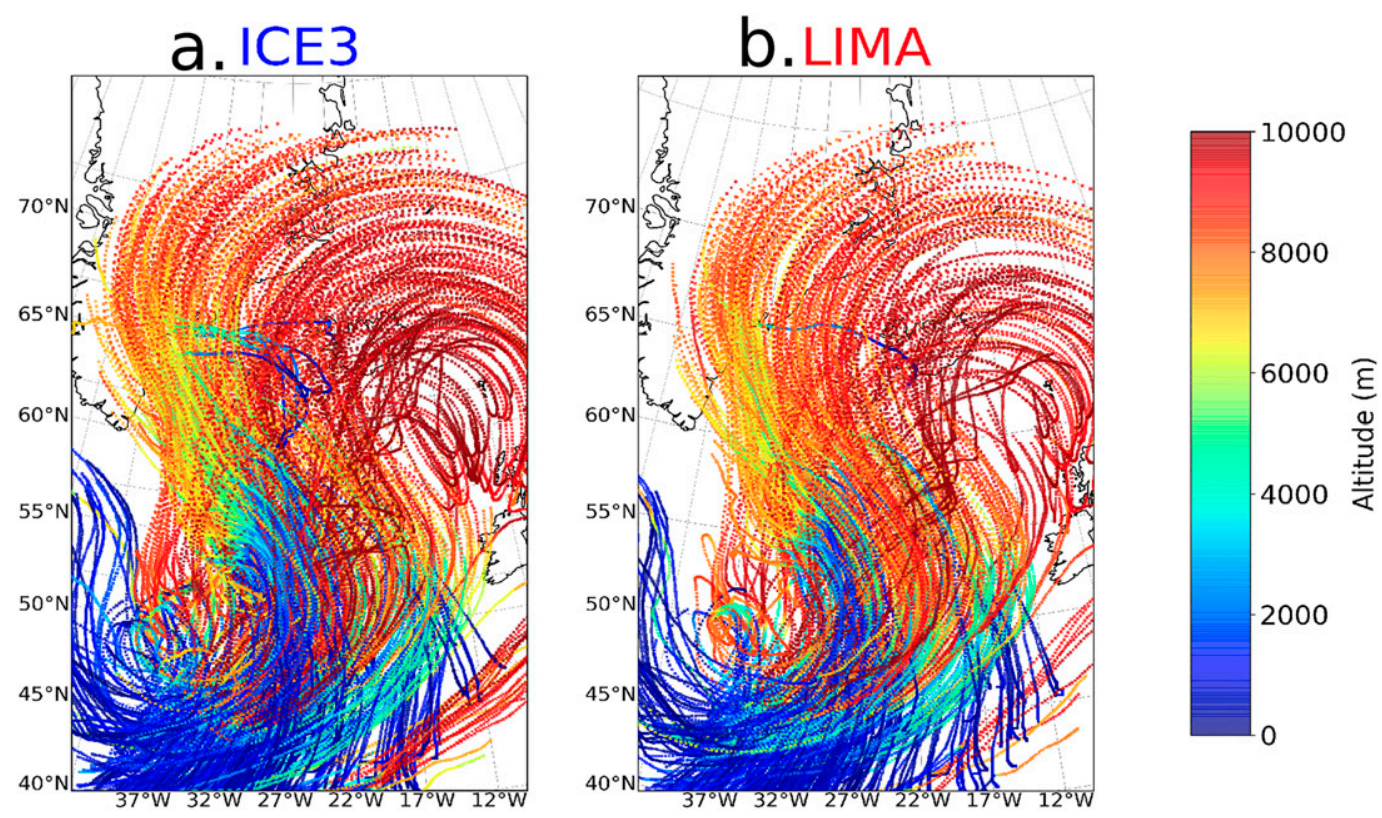

FIG. 2. WCB trajectories colored according to altitude for (a) ICE3 and (b) LIMA. Seeding has been performed in the whole domain every 8 grid points along the horizontal directions at 0000 UTC 3 Oct; 1 in 20 trajectories are plotted for the sake of visibility.

differences remain small suggesting that frontal risings are generally collocated in the two runs.

Figure $3 \mathrm{~b}$ shows the evolution of the five hydrometeor mass mixing ratios (ice, snow, graupel, rain, droplets). For both runs, the warm hydrometeors undergo a sudden increase during the first hour of the simulation while the cold hydrometeors are formed during the fifth hour. This suggests that the spinup of the model is less than $6 \mathrm{~h}$. Along these trajectories, the total hydrometeor mixing content in ICE3 is twice as high as in LIMA, mainly due to ice, snow and droplets contributions. These differences appear at the beginning of the simulations. In warm hydrometeor category, droplets mass mixing ratios are larger in ICE3 than LIMA but the reverse happens for rain mass mixing ratios. Consequently, highest hydrometeor contents along the WCB are droplets then snow for ICE3 and rain then snow for LIMA.

Figure $3 \mathrm{c}$ presents the heating rate budgets of the two simulations and Table 1 describes the different processes contributing to those budgets. While the total mass mixing ratio differs strongly between ICE3 and LIMA, the total heating rate does not exhibit large discrepancies between the two runs. Slight differences are, however, noticeable. During the first $18 \mathrm{~h}$ of the simulations, LIMA exhibits slightly higher total heating rates than ICE3 while the reverse tends to happen later during the second day of the simulations between 1000 and 1800 UTC 2 October. This is consistent with the sooner ascents of the LIMA trajectories inside the WCB and the fact that the ICE3 trajectories inside the WCB catch up the height of the LIMA trajectories during the second day (cf. Figs. 3a,c). While only slight differences are visible in the total heating rate, strong differences in processes contributing to this total are noticeable. ICE3 heating is mainly due to deposition on ice and droplets (DEPDI) while LIMA heating is due to deposition on ice and droplets (DEPDI), snow (DEPS), and graupel
(DEPG) by order of importance. There are many evidences that the relative importance of the different heating rates cannot be directly linked to the different hydrometeor mass mixing ratios. For instance, ICE3 exhibits greater snow mass mixing ratios than LIMA but the heating rate due to depositional growth and sublimation of snow is slightly negative in ICE3 and largely positive in LIMA. Hence, it mainly reflects sublimation of snow in ICE3 and results from the fact that snow can only be formed via autoconversion and aggregation of ice in ICE3 in cold clouds. The graupel mass mixing ratios are almost the same in the two schemes while the heating rate due to depositional growth and sublimation of graupel is positive in LIMA and near zero in ICE3. Here again, this is due to the fact that graupel is not formed via such a process in ICE3 in cold clouds. We also note that more cooling due to rain evaporation occurs in LIMA consistent with higher values of rain mass mixing ratios. Finally, in both schemes, the fourth process of importance is radiation. But because ICE3 exhibits a higher ice mass mixing ratio, the cooling due to radiation is slightly more important in ICE3.

To conclude, despite producing similar total heating rates on average along the WCB trajectories, the two simulations exhibit different heating budgets and the various processes contributing to the total heating rate are quite different. Furthermore, we saw that ICE3 produces $30 \%$ more WCB trajectories than LIMA. The following section is dedicated to more deeply investigate these differences in WCB processes and their impact on the uppertropospheric circulation.

\section{Impact on the ridge building}

Figures $4 \mathrm{a}$ and $4 \mathrm{~b}$ represent the PV at the $315-\mathrm{K}$ isentropic surface at 0000 UTC 3 October for ICE3 and LIMA, respectively, 


\section{a. Altitude evolution along WCBs}

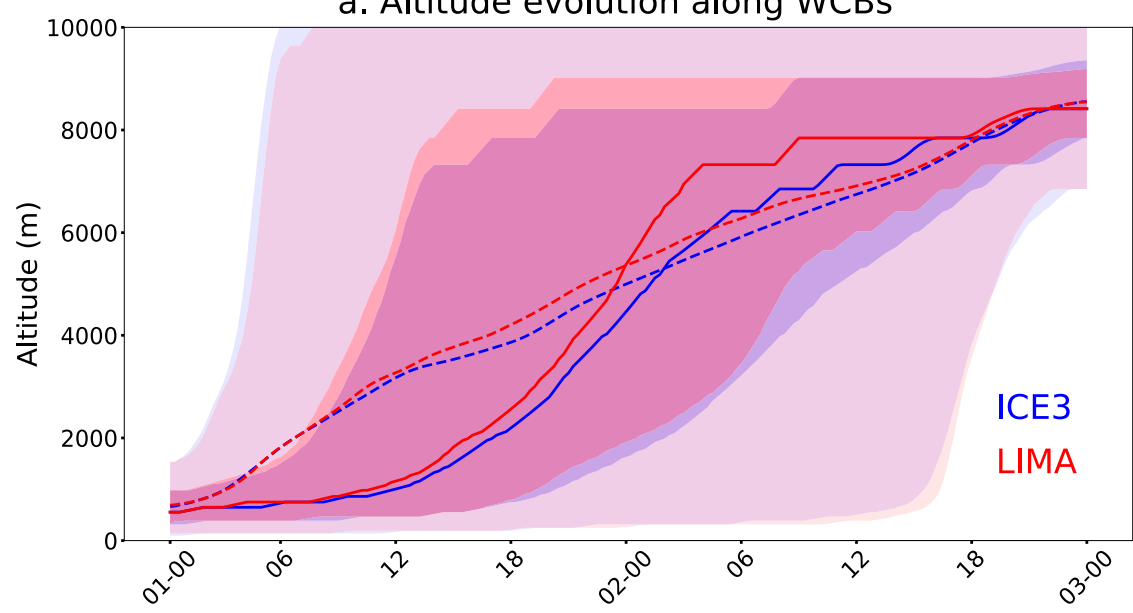

b. Mixing ratio evolution along WCBs

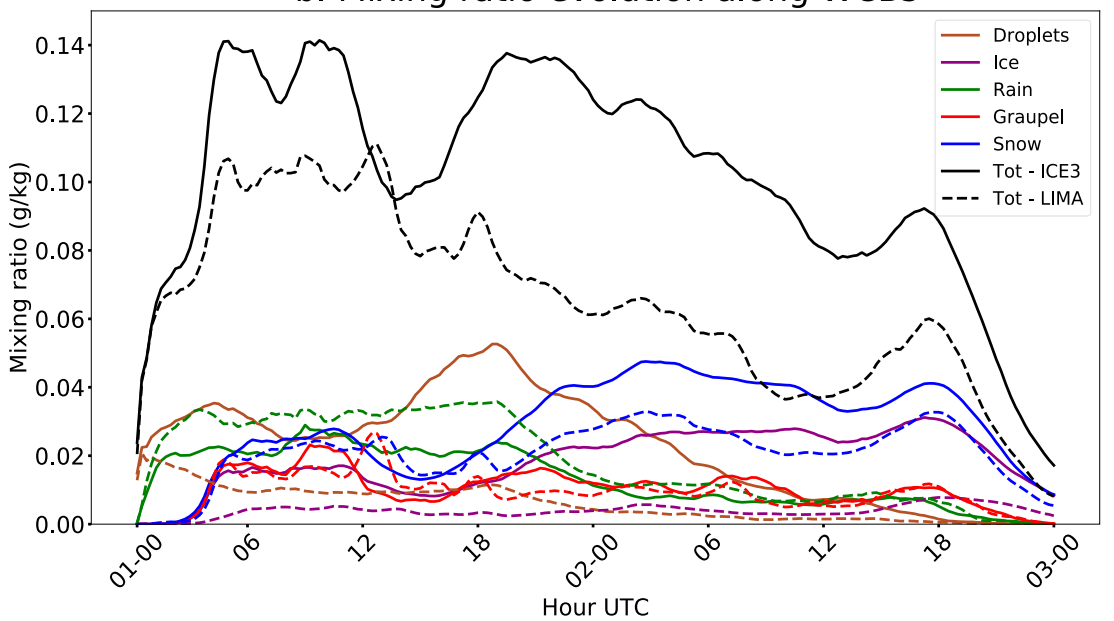

c. Heating rate evolution along WCBs

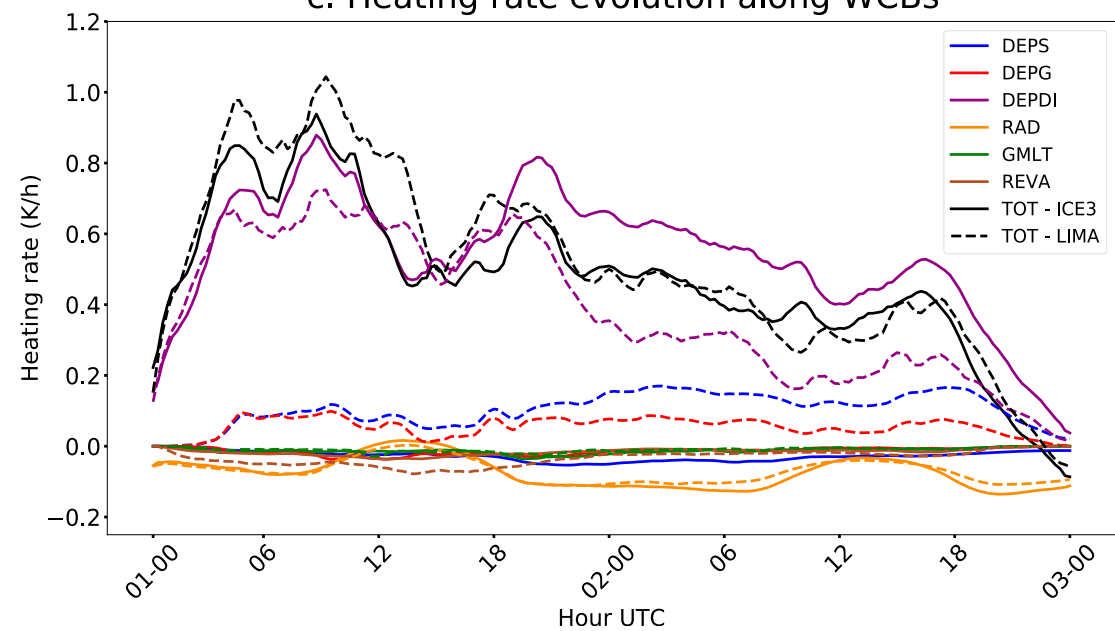

FIG. 3. (a) Time evolution of the altitude of the WCB trajectories between 0000 UTC 1 Oct and 0000 UTC 3 Oct. Light shadings represent the 5th and 95th percentiles and dark shadings the 25 th and 75 th percentiles, the full lines represent the median, and the dashed lines represent the mean. Time evolution of (b) the hydrometeor mass mixing ratios and (c) the heating rates of the main processes averaged over ICE3 (solid lines) and LIMA (dashed lines) trajectories. Abbreviations are given in Table 1. 
TABLE 1. Abbreviation of the main processes participating in the heating rate budget of the simulations.

\begin{tabular}{|c|c|}
\hline Abbreviation & Description of process \\
\hline DEPDI & Depositional growth of droplets and ice \\
\hline DEPS & $\begin{array}{l}\text { Depositional growth of snow/sublimation of } \\
\text { snow (ICE3, growth only in mixed phase) }\end{array}$ \\
\hline DEPG & $\begin{array}{l}\text { Depositional growth of graupel/sublimation of } \\
\text { graupel (ICE3, growth only in mixed phase) }\end{array}$ \\
\hline RAD & Radiative heating/cooling rate \\
\hline GMLT & Graupel melting \\
\hline REVA & Rain evaporation \\
\hline
\end{tabular}

and the difference is shown in Fig. 4c. The 2-PVU (1 PVU = $10^{-6} \mathrm{~K} \mathrm{~kg}^{-1} \mathrm{~m}^{2} \mathrm{~s}^{-1}$ ) limits used to identify the dynamical tropopause (Appenzeller and Holton 1997; Grewe and Dameris 1996; Blonsky and Speth 1998) are shown by dashed and solid green contours. Obviously, the most important discrepancies occur in the area of large PV gradient values, that is, in the vicinity of the tropopauses of the two simulations and in the stratosphere (left side of the 2-PVU limit). Two main and opposite anomalies appear between ICE3 and LIMA near the tropopauses. The first one has a narrow crescent shape spanning a large part of the ridge edge $\left(61^{\circ}-76^{\circ} \mathrm{N}\right.$ and $\left.25^{\circ}-53^{\circ} \mathrm{W}\right)$. It is hereafter called the red PV anomaly and corresponds to a $3^{\circ}$ northwestward shift of the tropopause with ICE3 compared to LIMA. The second one is more localized and located to the south of the ridge $\left(59.5^{\circ}-\right.$ $62.5^{\circ} \mathrm{N}$ and $\left.31^{\circ}-42^{\circ} \mathrm{W}\right)$. It is hereafter called the blue PV anomaly and corresponds to a $\sim 2^{\circ}$ southward shift of the tropopause with LIMA compared to ICE3. The differences in PV in those regions between LIMA and ICE3 are of the same order of magnitude as those found by Joos and Forbes (2016) while comparing two microphysics schemes used in IFS. The red PV anomaly forms from the beginning of the simulations at the leading edge of the ridge building while the blue PV anomaly begins to form $36 \mathrm{~h}$ later above the cold front and slightly north of it in convective regions as shown later. The two anomalies reflect spatial shifts of the tropopause region and changes in the PV gradient that has some consequences on the wind speed as discussed later in section 5 .

As expected, WCB trajectories are mainly inside the ridge. The red and blue WCB trajectories are defined as WCB trajectories being in the troposphere and belonging to the red and blue PV anomalies, respectively, in areas where the anomalies go beyond 1 PVU. After computation of the curvature of the WCB trajectories (or the relative vorticity along them) we found that the red and blue PV anomalies correspond to anticyclonic and cyclonic trajectories, respectively. Because they correspond to cyclonic trajectories forming above the cold front, blue WCB trajectories bring similarities with the WCB trajectories studied by Oertel et al. (2019) and Blanchard et al. (2020) that have fast convective ascents. This aspect will be confirmed later. Consistent with the negative sign of the PV anomalies and because more WCB trajectories mean more diabatically produced negative PV, ICE3 gets more WCB trajectories (723) inside the red PV anomaly than LIMA (260), while LIMA gets more WCB trajectories (101) reaching the blue PV anomaly than ICE3 (42).

\section{a. Anomaly at the leading edge of the ridge building}

This subsection is dedicated to studying the formation of the red PV anomaly appearing along the leading edge of the ridge building. Figures $5 \mathrm{a}, 5 \mathrm{~b}$, and $5 \mathrm{c}$ show the vertically averaged total heating rate between 2 and $9 \mathrm{~km}$ at 0000 UTC 2 October for ICE3, LIMA, and their difference, respectively. The large values of heating rate cover broader regions along the cold and bent-back warm fronts with ICE3 than LIMA. Figures 5e and $5 f$ show vertical cross sections of the meridionally averaged heating rate where most of the WCB trajectories ending up in the red PV anomaly (purple points) are located, that is along a significant part of the warm front (see the dark box in Figs. 5ac). At this time, most of the trajectories are near the tropopause above the large values of heating rate and tend to complete their ascent, and some of them are still in the upper side of the


FIG. 4. PV at the 315-K isentropic surface for (a) ICE3, (b) LIMA, and (c) the difference LIMA-ICE3 at 0000 UTC 3 Oct. The 2-PVU isoline is represented by a green full and dashed line for ICE3 and LIMA, respectively. In (a) and (b), WCB trajectories intersecting the isentrope $315 \pm 5 \mathrm{~K}$ at the plot time are shown in black dots. Purple and cyan dots represent the WCB trajectories corresponding to the red and blue PV anomalies shown along the tropopause in (c) (see text for more details on the definition of the anomalies). Only 1 WCB in 5 are represented for visibility sake. 


\section{Vertically averaged heating rate at 18 UTC 2 Oct}
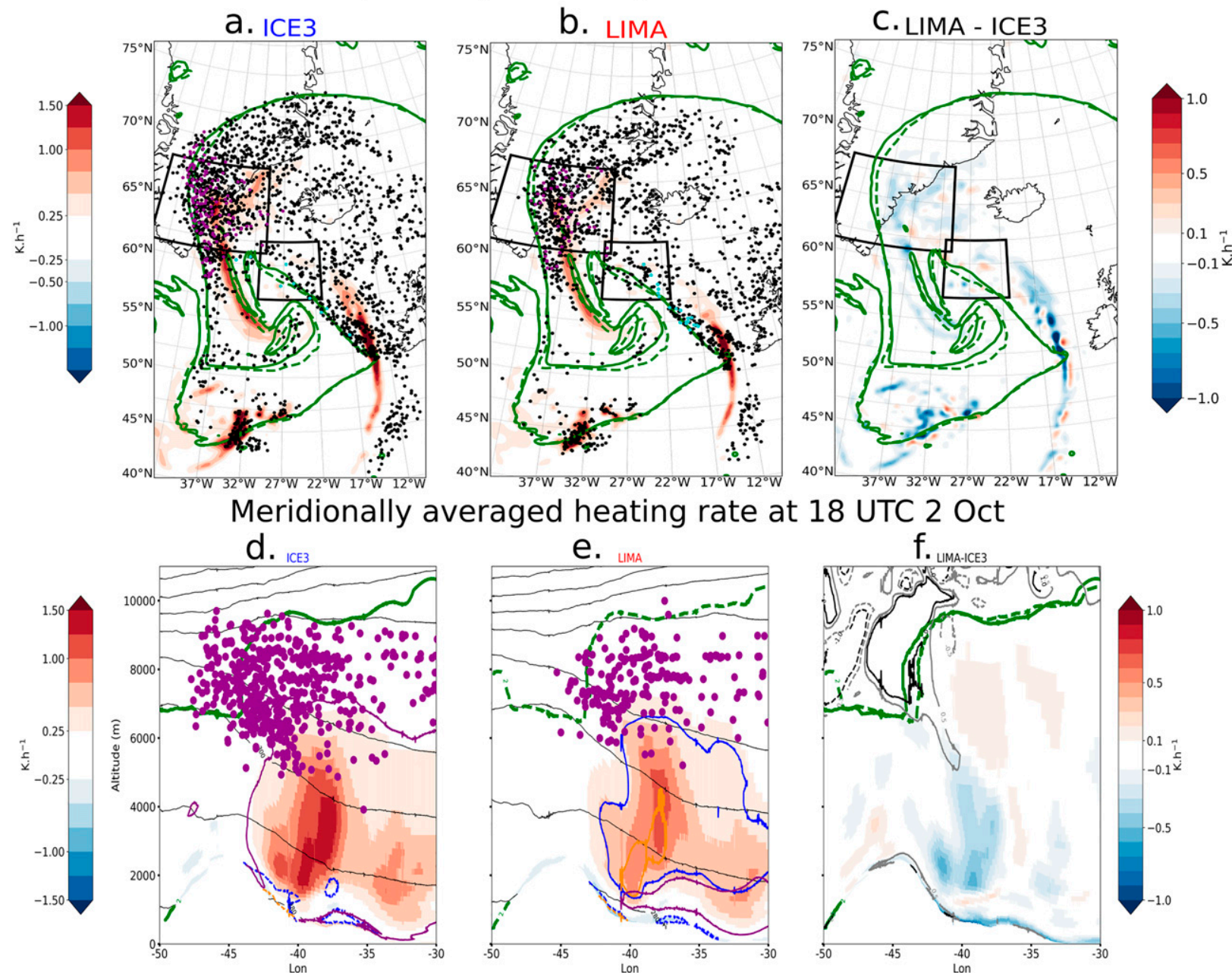

FIG. 5. (top) Vertically averaged heating rate between 2 and $9 \mathrm{~km}$ (shadings) and (bottom) meridionally averaged heating rate (shadings) in the larger black area shown in the top panels at 1800 UTC 2 Oct for (a),(d) ICE3; (b),(e) LIMA; and (c),(f) the difference LIMA-ICE3. Black dots in (a) and (b) correspond to WCB trajectories positions at 1800 UTC 2 Oct, while the purple and blue dots correspond to the trajectories ending in the red and blue PV anomalies, respectively, shown in Fig. 4c. In the top panels $1 \mathrm{WCB}$ in 5 are represented for visibility sake. Green lines represent the position of the dynamic tropopause (full line in ICE3 and dashed line in LIMA). The gray and black lines in (f) represent the 1- and 0.5-PVU difference between LIMA and ICE3 (solid lines for positive and dashed for negative). The purple, blue, and orange lines in (e) and (f) represent the DEPDI, DEPS, and DEPG contributions, respectively, when it is greater than $0.3 \mathrm{~K} \mathrm{~h}^{-1}$ (solid for positive and dashed for negative).

strong heating area. On these cross sections, we also see that the strong heating area is larger in ICE3 and the peak values of the heating rate are $50 \%$ higher in ICE3 than LIMA (about $1.5 \mathrm{~K} \mathrm{~h}^{-1}$ for ICE3 and $1.0 \mathrm{~K} \mathrm{~h}^{-1}$ for LIMA). Above $2 \mathrm{~km}$, that is mainly above the melting layer, the most important processes contributing to the heating rate are deposition on ice with ICE3 and deposition on snow and graupel for LIMA (Figs. 5d,e). Below $2 \mathrm{~km}$, condensational growth of droplets dominates for both schemes. In agreement with the PV tendency equation, stronger diabatic heating leads to stronger vertical gradient aloft and stronger PV destruction in ICE3 than in LIMA. We also checked that the divergent winds are more intense in the former run than in the latter, leading to more intense PV advection which amplifies more rapidly the ridge in ICE3. The differential heating $(\sim 0.5 \mathrm{~K}$ at maximum $)$ between ICE3 and LIMA likely explains the $1^{\circ}$ tropopause shift between ICE3 and LIMA (Fig. 5f) via its direct effect (PV destruction) and its indirect effect ( $\mathrm{PV}$ advection by divergent winds).

Figure 6 shows the temporal evolution of height and potential temperature tendencies associated with the main microphysical processes (deposition on droplets and ice, on snow and on graupel) for the WCB trajectories corresponding to the red PV anomaly. As expected, rapid ascents co-occur with intense heating rates in both runs (Figs. 6a,c). However, the timing of the largest total heating rates strongly differs 
a. Altitude evolution

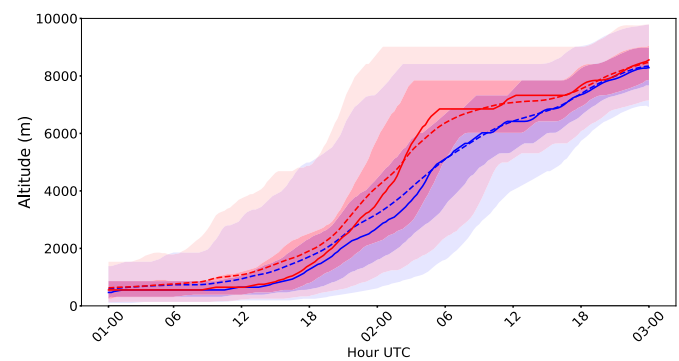

b. Cumulated number of trajectories ascending $600 \mathrm{hPa}$ from 00 UTC on 1 Oct



c. Total heating rate

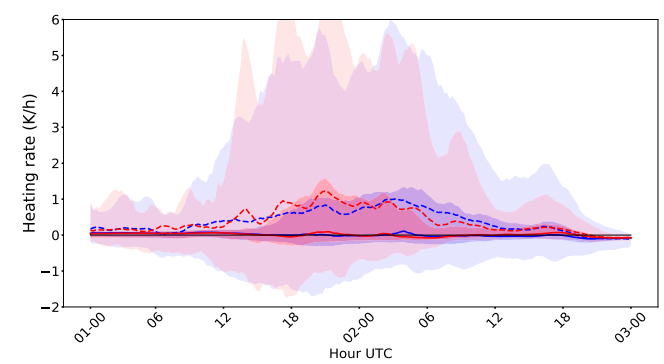

d. Heating due to DEPDI (droplets/ice)



e. Heating due to DEPS (snow)



f. Heating due to DEPG (graupel)

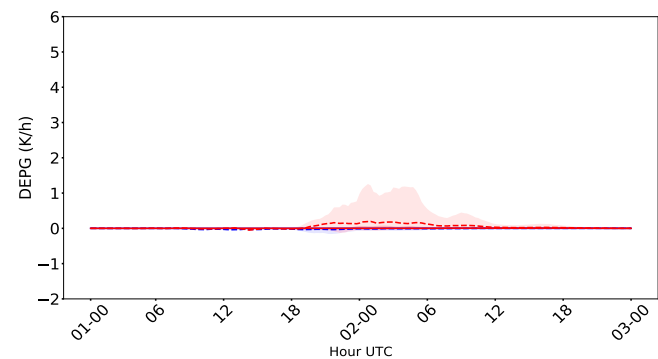

FIG. 6. Time evolution between 0000 UTC 1 Oct and 0000 UTC 3 Oct along the computed WCB trajectories reaching the red PV anomaly of (a) altitude, (c) the total heating rates, (d) the heating rate due to deposition of vapor on droplets or ice, (e) the heating rate due to the deposition of vapor on snow, and (f) the heating rate due to the deposition on graupel. Light shadings represent the 5 th and 95 th percentiles and dark shadings the 25 th and 75 th percentiles, the full lines represent the median, and the dashed ones represent the mean. (b) Number of trajectories reaching the red PV anomaly at 0000 UTC 3 Oct and having ascended $600 \mathrm{hPa}$ between the initial time and a given time (blue for ICE3 and red for LIMA).

between ICE3 and LIMA. Between 1200 UTC 1 October and 0000 UTC 2 October, the heating is slightly stronger in LIMA due to strong condensational growth of droplets as mass mixing ratios indicate the presence of droplets and not ice at that time (not shown). As a consequence, the WCB ascends faster in LIMA during that period. During the next $6 \mathrm{~h}$, between 0000 and 0600 UTC 2 October, the two total heating rates are roughly equivalent and the WCB trajectories exhibit the same order of elevation in the two runs (Figs. 6a,c). Between 0600 UTC 2 October and 0000 UTC 3 October, the heating is stronger for ICE3 due to stronger depositional growth of ice which is not compensated by the stronger heating due to deposition on graupel and snow for LIMA (Figs. 6c-f).

Figure $6 \mathrm{~b}$ shows the number of trajectories that have already ascended to $600 \mathrm{hPa}$ since the initial time starting at zero by construction. The first trajectories ascending to $600 \mathrm{hPa}$ appear at 1800 UTC 1 October. While the averaged heating along those WCB trajectories is initially stronger for LIMA, the number of trajectories satisfying $600-\mathrm{hPa}$ ascents never exceeds that for ICE3 (Fig. 6b). However, we do see that the difference in the number of trajectories accentuates robustly after 0600 UTC 2 October due to stronger depositional growth of ice in ICE3 (Figs. 6c,d).

To conclude, the ICE3 WCB trajectories reaching the red PV anomaly are more numerous than the LIMA WCB trajectories arriving in that region because the heating is stronger and spans larger areas in ICE3 to the north of the cyclone. This does not mean that the heating averaged along the selected WCB trajectories is stronger in ICE3. But the processes leading to the heating largely differ. Adjustment to saturation on ice performed in ICE3 and not in LIMA (explicit deposition) may explain the more important vapor deposition on ice in ICE3, its stronger heating in average at upper levels and the more numerous WCB trajectories found for that scheme. This 


\section{Vertically averaged heating rate at 18 UTC 2 Oct}
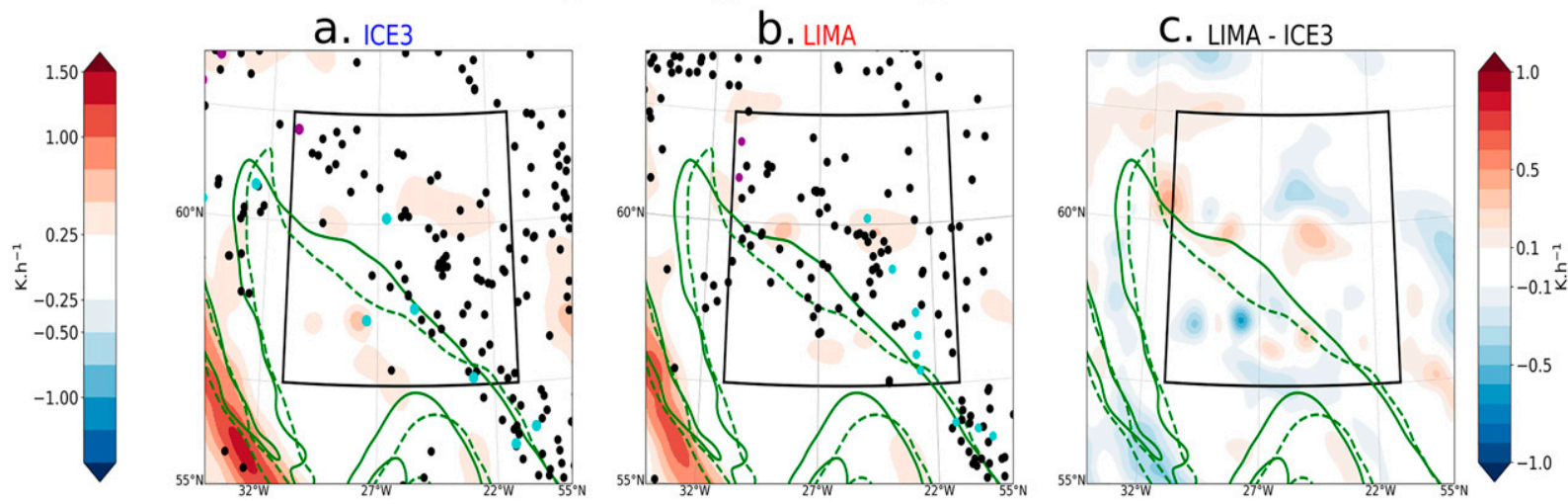

\section{Zonally averaged heating rate at 18 UTC 2 Oct}
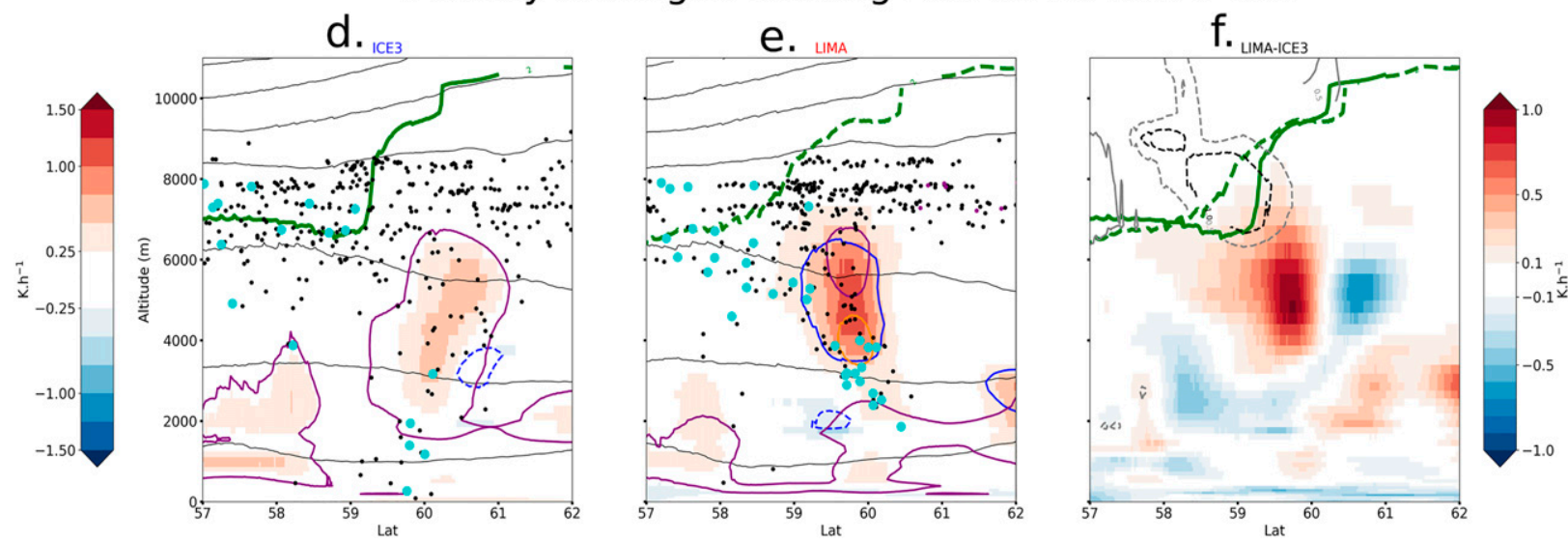

FIG. 7. (top) As in Figs. 5a-c but in the zoomed area centered on the small black box. (bottom) Zonally averaged heating rate (shadings) in the black area shown in the top panels for (a),(d) ICE3; (b),(e) LIMA; and (c),(f) the difference LIMA-ICE3. Color, dots, and lines legends are as in Fig. 5.

picture of the WCB trajectories finishing their trajectories in the red PV anomaly reflects the difference between the WCB trajectories of ICE3 and LIMA in general. However, in some areas, the situation might be different as discussed in next subsection.

\section{b. Anomaly in the cyclonic branch of the WCB}

WCB trajectories contributing to the formation of the blue PV anomaly shown in Fig. 4 are mainly located above the cold front on its northern part at 1800 UTC 2 October (Figs. 5a,b). To better visualize the heating rates and WCB trajectories in that region, a zoom is made in Fig. 7. The formation of the blue $\mathrm{PV}$ anomaly is already seen by the more southwestward shift of the tropopause in LIMA compared to ICE3 (see solid and dashed green contours). This region is characterized by less homogeneous heating rates than farther south along the cold front and is more marked by isolated patches of heating rate suggesting the presence of embedded convection on the northern edge of the cold front similarly to Oertel et al. (2021) or Blanchard et al. (2020) (see, e.g., at $29^{\circ} \mathrm{W}$ and $59.5^{\circ} \mathrm{N}$ for both runs). Ascents of these WCB trajectories are fast for the ensemble of the trajectories $(600 \mathrm{hPa}$ in $\sim 12 \mathrm{~h}$ ) and some individual ascents are even faster, confirming the presence of convection. By zonally averaging the heating rate on $21^{\circ}-31^{\circ} \mathrm{W}$, it clearly appears that the localized heating rate near $60^{\circ} \mathrm{N}$ is much stronger in LIMA with the peak values being above $1.5 \mathrm{~K} \mathrm{~h}^{-1}$ for LIMA and slightly less than $1.0 \mathrm{~K} \mathrm{~h}^{-1}$ for ICE3. As for the other WCB trajectories, the heating in the ice phase is mainly due to vapor deposition on ice for ICE3 and vapor deposition on snow and graupel for LIMA (see Figs. 7d,e). However, in that particular case, the depositional growth of snow and graupel in LIMA is larger than the depositional growth of ice in ICE3 in contrast with many other regions and in particular the red PV anomaly discussed earlier. In Fig. 7, the negative PV anomaly and the shift between the two tropopauses being just above the heating rate anomaly, it suggests that the vertical gradient of the heating is important to create the PV anomaly and not necessarily the horizontal gradient as in Oertel et al. (2021) or Blanchard et al. (2021). The interpretation of the formation of the negative PV anomaly is confirmed by the presence of more numerous WCB trajectories in LIMA than ICE3 between $59^{\circ}$ and $61^{\circ} \mathrm{N}$ above $6 \mathrm{~km}$. As the divergent wind is northward in both runs in the vicinity of this anomaly, and not oriented toward the stratospheric reservoir it suggests that there is no reinforcement of this anomaly 
a. PV difference at 10 UTC
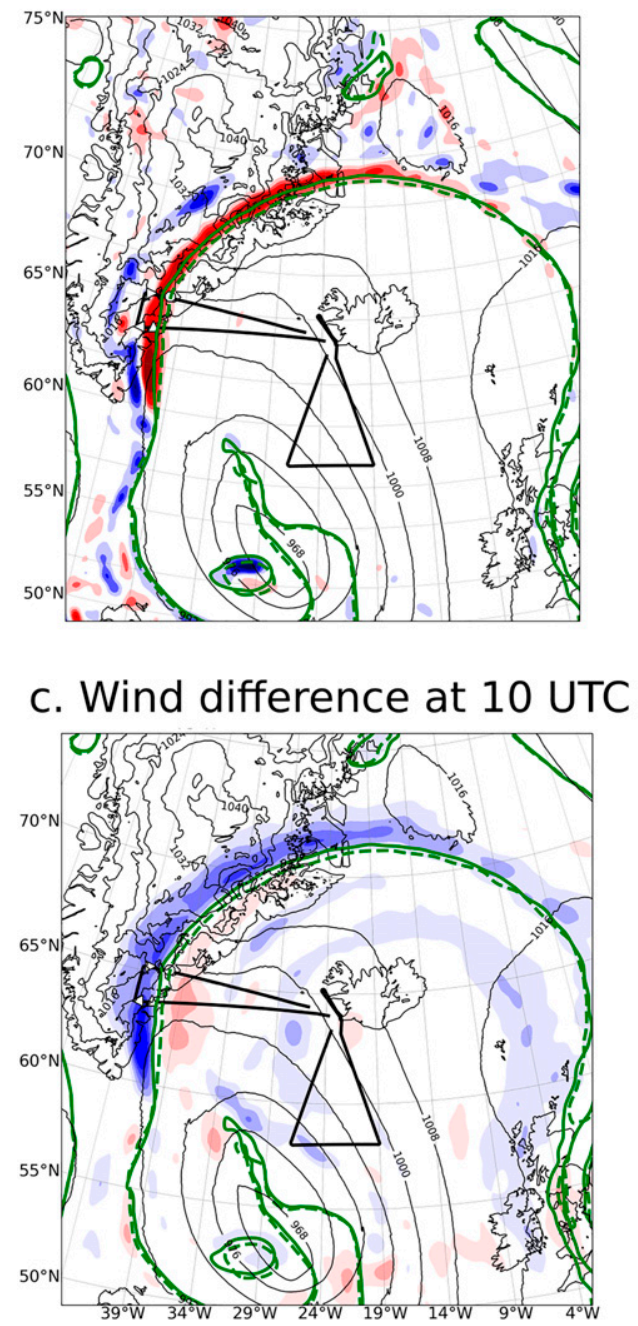

b. PV difference at 16 UTC

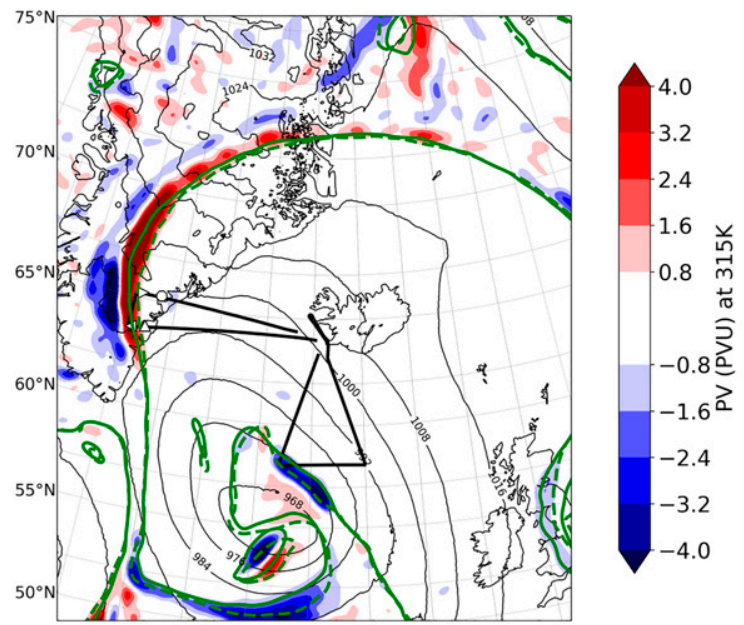

d. Wind difference at 16 UTC

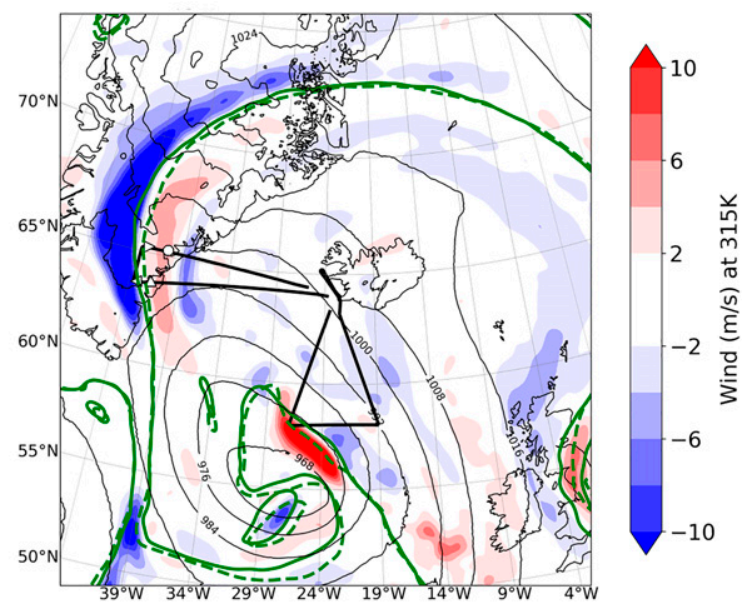

FIG. 8. (a),(b) PV and (c),(d) wind difference LIMA-ICE3 at the 315-K isentropic surface at (left) 1000 UTC 2 Oct and (right) 1600 UTC 2 Oct. F6 flight track (from $\sim 0900$ to $\sim 1130$ UTC) is represented by the top-left triangle. F7 flight track (from $\sim 1300$ to $\sim 1600$ UTC) is represented by the bottom triangle.

by the indirect effect of PV advection by the divergent winds (not shown). This is to be contrasted with the case of the red anomaly for which the divergent winds participate in reinforcement of the anomaly.

To sum up, the blue PV anomaly seems to be a consequence of discrepancies between the two simulations in the activity of isolated convective cells on the northern leading edge of the cold front. Since the two runs largely differ in the vicinity of the tropopauses, next section is dedicated to identify which run performs better when compared to the observations.

\section{Comparison between model simulations and observations}

Figure 8 shows the PV and the wind differences between LIMA and ICE3 roughly at the time of the flights: at 1000 UTC for flight F6 that last from $\sim 0900$ to $\sim 1130$ UTC (Figs. 8a,c) and at
1600 UTC for flight F7 that last from $\sim 1300$ to $\sim 1600$ UTC (Figs. 8b,d). Flight F6 intersects the red PV anomaly in the morning (Fig. 8a). The PV gradient differences associated with the PV anomaly along the tropopause are responsible of a dipolar wind anomaly with larger negative than positive values (see blue and red shaded areas in Fig. 8c on both sides of the tropopauses). This creates a broader and more northwestward shifted jet stream in ICE3 than LIMA. Flight F7 is in the vicinity of the blue PV anomaly when it starts to be formed (Fig. 8b). This creates higher wind speed values in the southwestern corner of the flight for LIMA than ICE3 (Fig. 8d). Since flights F6 and F7 crossed the red and blue PV anomalies, respectively, airborne measurements are well suited to evaluate the skills of the two simulations.

\section{a. Satellite}

Before comparing with dropsondes and RALI retrieved data, a comparison of the brightness temperatures at $10.8 \mu \mathrm{m}$ as 


\section{a. ICE3}



b. LIMA

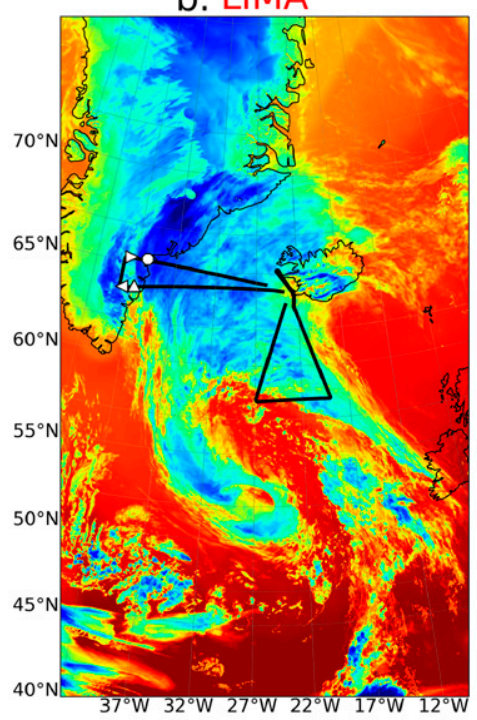

C. OBS

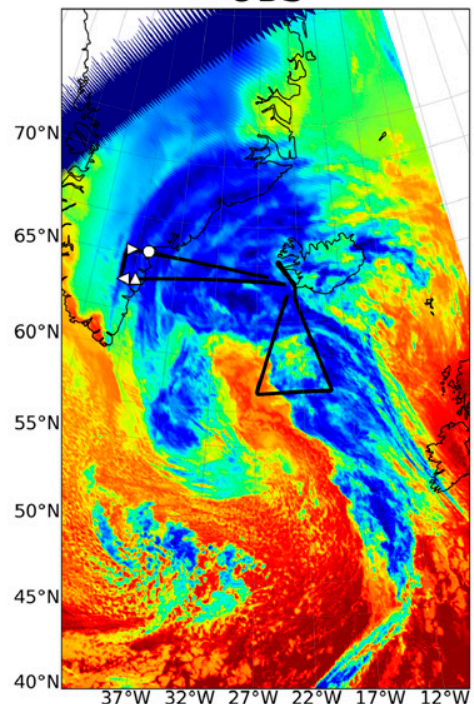

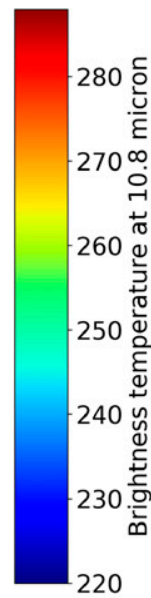

220

FIG. 9. Brightness temperature at $10.8 \mu \mathrm{m}$ at 1200 UTC 2 Oct 2016 for the (a) ICE3, (b) LIMA, and (C) the MSG observation. The black lines represent the two flight tracks.

simulated by ICE3 and LIMA with the observed one from the Meteosat Second Generation (MSG) satellite (Schmetz et al. 2002) is made in Fig. 9. To estimate the cloud brightness temperature at $10.8 \mu \mathrm{m}$ as viewed by a satellite, the Radiative Transfer for TOVS (RTTOV) version 11.3 fast radiative transfer model is used (Saunders et al. 2013). The comparison is made at 1200 UTC 2 October, as it is the closest intermediate time between the two flights for which we have satellite data. The dark and light blue shadings indicate the presence of high and mid-tolow clouds, respectively, while the dark red represents the sea surface temperature. Three main regions of high clouds can be detected from the satellite product in Fig. 9c: a band near $19^{\circ}-13^{\circ} \mathrm{W}$ extending from $44^{\circ}$ to $60^{\circ} \mathrm{N}$ and corresponding to the high clouds associated with the cold front, the WCB outflow region where flight $\mathrm{F} 6$ was located and another region between $37^{\circ}-$ $31^{\circ} \mathrm{W}$ and $54^{\circ}-60^{\circ} \mathrm{N}$ near the bent-back warm front. The red part on the southwestern corner of flight F7 situates the dry intrusion.
The most obvious difference between the model and the observations is that the cloud top is warmer in the simulations. This discrepancy is more pronounced with LIMA, which possibly means that LIMA does not simulate clouds as high as ICE3 does. Otherwise, the ICE3 and LIMA simulations seem to correctly represent the position of the fronts and WCB.

\section{b. Dropsondes}

The wind speed profiles observed by the dropsondes launched during F6, in particular the four westernmost dropsondes labeled as "095544," "100414," "102617," and "103200," allow us to assess the skills of the two simulations in representing the location of the tropopause and the upper-level winds (Fig. 10). These dropsondes are particularly well suited to compare the skills of the LIMA and ICE3 simulations as they are located within the red PV anomaly (Fig. 8a). At upper levels, between 8 and $10 \mathrm{~km}$, the two dropsondes 095544 and 103200 exhibit a. 095544

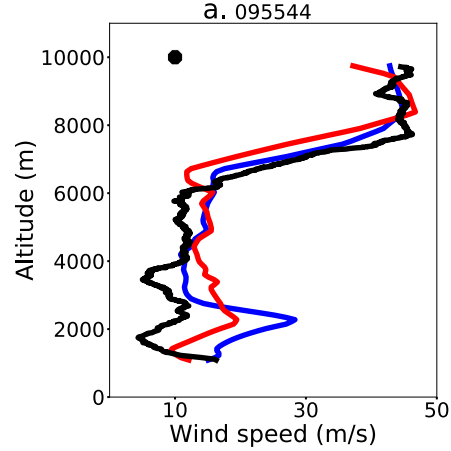

b. 100414

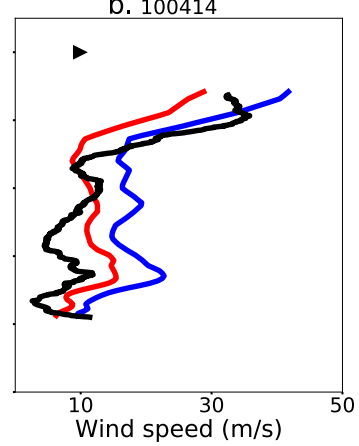

C. 102617

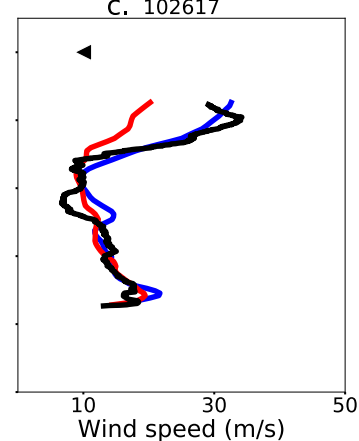

d. 103200



FIG. 10. Wind speed as observed (in black) from the four westernmost dropsondes launched during F6 over Greenland coast (see symbols in Figs. 4 or 9 indicating the launch location for each dropsonde) and simulated with ICE3 (in blue) and LIMA (in red). Each dropsonde is labeled according to the launch time using the format hhmmss. 
Wind speed

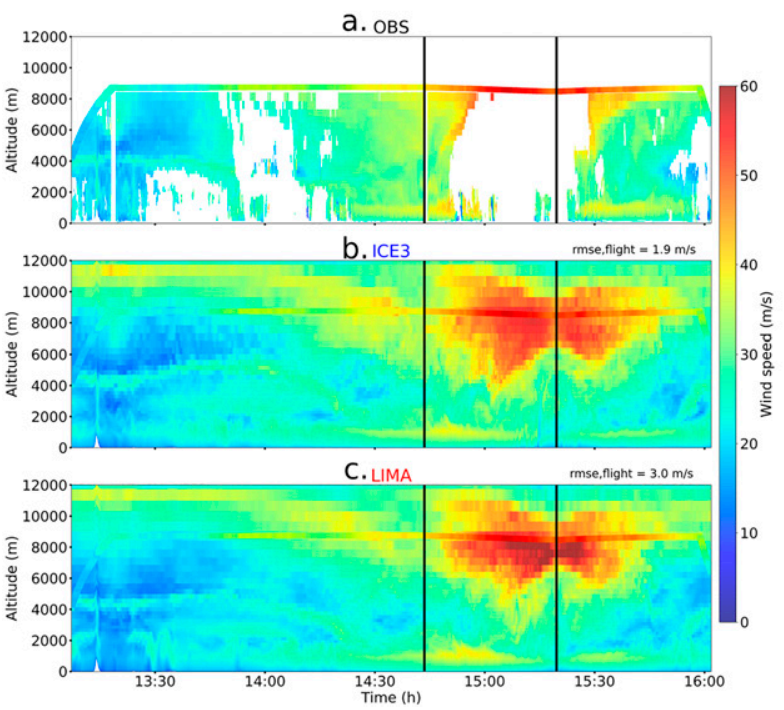

Radar reflectivity

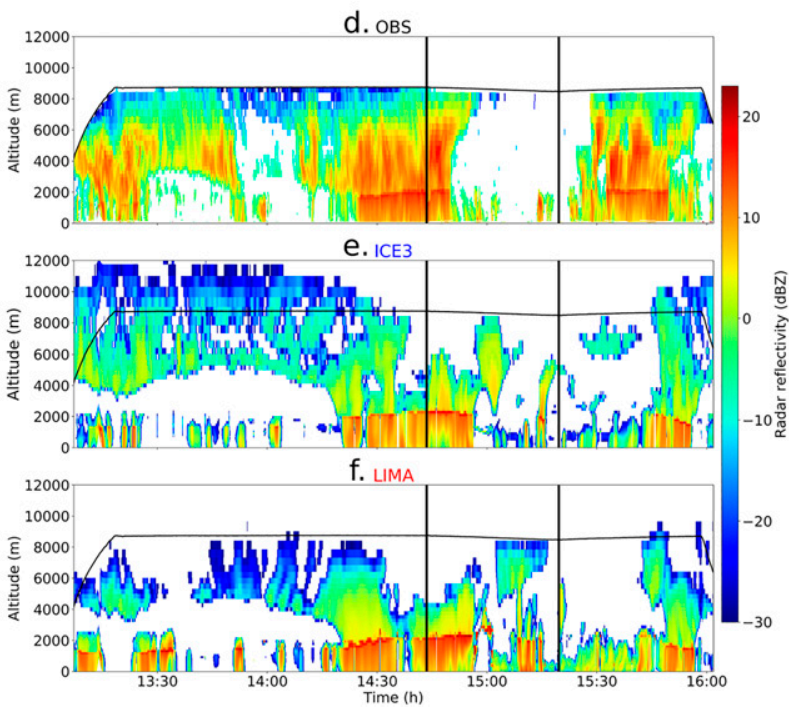

FIG. 11. (a)-(c) Horizontal wind speed and (d)-(f) reflectivity along flight F7 (see bottom triangle in Fig. 9) for (top) RASTA observations, (middle) ICE3 simulation, and (bottom) LIMA simulation. The vertical dark lines stand for the time where the flight changed direction. Wind speed as measured by the in situ aircraft instrument at the flight level are added on (a)-(c) with the same color bar. The RASTA data are regridded onto the MésoNH grid.

observed wind speed values near $45 \mathrm{~m} \mathrm{~s}^{-1}$ which are rather well represented by the two simulations. The two others, namely, 100414 and 102617 , located to the extreme west of the flight show observed values near $30 \mathrm{~m} \mathrm{~s}^{-1}$. For those two dropsondes, strong discrepancies appear between LIMA and ICE3 simulations; LIMA underestimates the observed values between 8 and $10 \mathrm{~km}$ while ICE3 is much closer to the observations at those heights. This is particularly cogent in Fig. 10c. This corresponds to the negative wind anomalies shown in Fig. $8 \mathrm{c}$ and associated with the red PV anomaly of Fig. 8a. Our conclusion is that ICE3 better represents the upper-level wind speeds in the region of the red PV anomaly, and that the position of the tropopause in ICE3 is more realistic than in LIMA.

\section{c. Remote sensing measurements}

Figure 11 shows the wind and reflectivity as measured by the radar below the aircraft and as simulated by ICE3 and LIMA along flight F7. The aircraft flew along the central triangle shown in Fig. 9 by following a clockwise path. Since the radar is only sensitive to hydrometeors, observations are only available in cloudy and precipitating areas. Even though the jet stream is crossed twice only the wind speed values on its northern flank are measured by the radar and the blank values between 1500 and 1530 UTC correspond to the flank of the jet stream within the dry intrusion. In situ airborne measurements of wind speed correlate fairly well with the radar measurements (Fig. 11a). Wind patterns are correctly represented by ICE3 and LIMA in regions where radar observations exist.

In LIMA, the jet is stronger and narrower than in ICE3 as already shown in Fig. 8d in relation with the blue PV anomaly. The spatial extension of the jet stream is slightly better represented with ICE3 (see in situ data at 1545 UTC) and the peak values of the jet stream are also more consistent with observed ones in ICE3 (between 1510 and 1530 UTC). This is confirmed by the root-mean-square values along the flight which are lower with ICE3 $\left(1.9 \mathrm{~m} \mathrm{~s}^{-1}\right)$ than LIMA $\left(3.0 \mathrm{~m} \mathrm{~s}^{-1}\right)$.

Figure $11 \mathrm{~b}$ compares the observed and simulated reflectivities. There is no observed reflectivity above $8 \mathrm{~km}$ because the aircraft flew at this altitude and the radar was only pointing downward. Many features of the observed reflectivity are found in the simulated reflectivity like the strong reflectivity near 1430 and 1545 UTC corresponding to deep cloudy structures along the WCB. The dry area in between these two regions is also represented. Another common feature between the simulations and the observations is the altitude of the melting layer located near $2 \mathrm{~km}$. However, very important discrepancies appear and the skills of the simulations strongly depend on the altitude.

Below the melting layer, the reflectivity values are rather well reproduced by the model (see Figs. 11d-f and Figs. 12a-c). This is particularly true for LIMA (see the pdfs Figs. 12a-c). Root mean squared errors are indeed only $1.6 \mathrm{~dB} Z$ for LIMA and $2.8 \mathrm{~dB} Z$ for ICE3.

Above the melting layer, in the middle troposphere between 2 and $6 \mathrm{~km}$, the reflectivity values are largely underestimated in the simulations compared to the observations, about $5 \mathrm{~dB} Z$ for ICE3 and about $10 \mathrm{~dB} Z$ for LIMA. At this altitude, snow and graupel predominate. This might be due to the fact that snow mass-concentration distribution disagrees with observations as shown in Taufour et al. (2018). Besides, the current radar simulator uses Mie scattering rather than other complex methods, such as the T-matrix, and this may suffer from rather large errors in the solid phase and may underestimate the reflectivity (e.g., Hogan et al. 2012; Borderies et al. 2018). 
a. ICE3

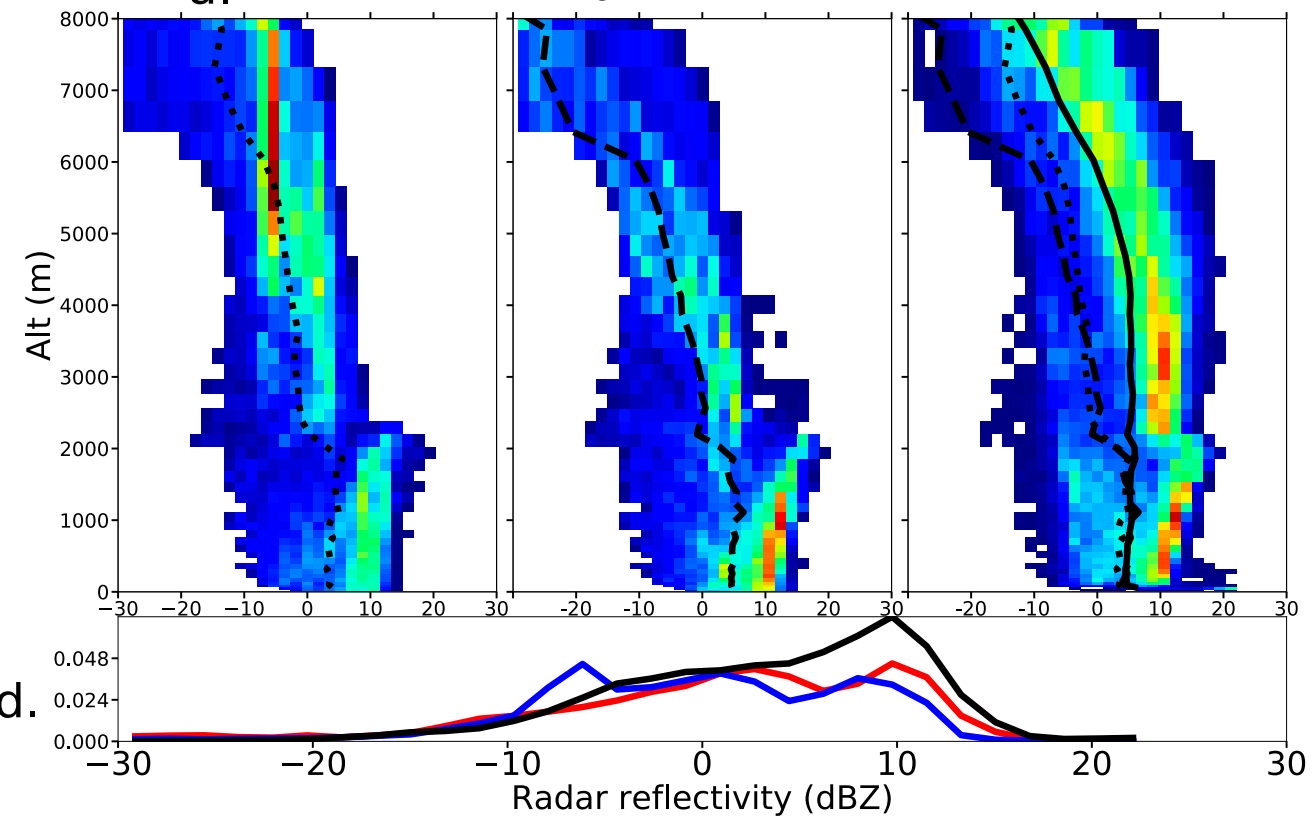

c. OBS

b. LIMA





FIG. 12. Bivariate PDFs as a function of altitude of (a)-(c) reflectivity and (e)-(g) ice water content for ICE3 in (a) and (e), LIMA in (b) and (f), and the observations regridded onto the model grid in (c) and (g), where mean vertical profiles are indicated for ICE3 (dotted line), LIMA (dashed line), and observations (solid line). The measurements and observations are normalized with the total number of points. (d),(h) The sum over height of the bivariate PDFs of wind speed and IWC, respectively, with ICE3 (in blue), LIMA (in red), and observations (in black).

In the upper troposphere, between 6 and $8 \mathrm{~km}$, ICE3 reflectivity is higher than LIMA reflectivity and is close to the observed reflectivity: ICE3 reflectivity varies between -5 and $-15 \mathrm{~dB} Z$ on average as in the observations while LIMA reflectivity is below $-20 \mathrm{~dB} Z$ at those heights (see black curves in Figs. $12 \mathrm{a}-\mathrm{c}$ ). At altitudes higher than $8 \mathrm{~km}$, where there is no observed reflectivity for that flight, LIMA still simulates much weaker reflectivity than ICE3. This suggests that fewer 
hydrometeors are present in LIMA at high altitude. It is consistent with Fig. 9 where cloud top temperatures are found to be warmer and likely lower in altitude with LIMA than ICE3.

When considering the variations with height of the reflectivity, LIMA presents the closest shape to the observations as both LIMA and the observed reflectivity values decrease with height from 3 to $8 \mathrm{~km}$ while ICE3 reflectivity values do not present such a decrease. More precise vertical distribution with LIMA could be due to a more accurate cold species distribution and vapor depositional growth. Indeed, LIMA uses an explicit vapor deposition on snow, graupel and ice, while ICE3 uses one supersaturation distribution for ice and another one for graupel and snow in mixed-phase clouds. When a vertical integration is made, LIMA reflectivity is also slightly greater than ICE3 but this results from the warm phase below the melting layer (Fig. 12d). As previously said, ICE3 has higher reflectivity than LIMA in cold phase and in that sense is closer to the observations.

Model-to-radar and radar-to-model approaches are complementary to address the weaknesses associated with the assumptions inherent to both approaches. Figures $12 \mathrm{e}-12 \mathrm{~h}$ compare PDFs of ice water content (IWC). As with the reflectivity, we only consider IWC values that can be retrieved with RALI in our comparison. A log scale is also used to get closer to the reflectivity variable, which is shown in decibels. Above $6 \mathrm{~km}$, ICE3 is close to the observations and clearly exhibits greater values than LIMA: ICE3 ice water content fluctuates between 0.03 and $0.1 \mathrm{~g} \mathrm{~m}^{-3}$ roughly like the retrieved ice water content while LIMA ice water content values are much lower between 0.01 and $0.05 \mathrm{~g} \mathrm{~m}^{-3}$. Below 6-km height, LIMA and ICE3 strongly underestimate the quantities of cold species compared to the observations but LIMA produces a more realistic vertical distribution. The main conclusions concerning the reflectivity PDFs are thus confirmed when looking at the IWC PDFs. Therefore the main differences between the simulations and the observations are unlikely to be attributed to the way the reflectivity is calculated in the models or the way IWC is retrieved. These underestimations could be attributed to microphysical misrepresentations like the hydrometeors fall speed or mass-diameter distribution. Also, vertically integrated water content could be lower than reality due to misrepresented airsea exchanges.

To sum up, MésoNH reproduces the observed wind very well. However, the two simulations clearly underestimate the IWC and reflectivity above the melting layer. LIMA produces the closest variations with altitude but ICE3 is better in intensity. As previously hypothesized, adjustment to saturation in cold and mixed phases realized only by ICE3, may explain why ICE3 produces more cold hydrometeors but prognostic vapor deposition on parallel on ice, snow and graupel with LIMA may explain the better vertical profile of cold hydrometeor contents.

\section{Conclusions and discussion}

The present study is part of a joint international effort under the banner of the NAWDEX field campaign to better assess the skills of NWP models in representing subgrid-scale diabatic processes within midlatitude cyclones. It more precisely investigates the impact of two cloud microphysical schemes developed within the mesoscale MésoNH model on the development of an extratropical cyclone during IOP6, called the "stalactite cyclone," its associated warm conveyor belt, and the ridge building aloft. Two 72-h simulations with a $2.5-\mathrm{km}$ resolution are performed and compared: one with the one-moment scheme ICE3 and the second one with the quasi two-moment scheme LIMA. ICE3 and LIMA also differ on the processes of vapor deposition on hydrometeors in cold and mixedphase clouds.

The first part of the study was dedicated to presenting differences in WCB trajectories, hydrometeor mixing ratios and heating rates along the WCB and how these differences impact the upper-level ridge building in the WCB outflow region. The following results were found:

- A strong heating rate covers larger areas along the cold and bent-back warm front in ICE3 than LIMA. This explains why WCB trajectories in ICE3 are $33 \%$ more numerous than in LIMA even though the averaged total heating rates along them are equivalent. In comparison, Joos and Forbes (2016) found the same number of WCB trajectories by running their model with two distinct microphysical schemes.

- Despite having roughly the same heating rate along WCB trajectories, the hydrometeor contents and the processes participating in the heating budget along WCB trajectories largely differ from one run to another. Latent heating in ICE3 is dominated by deposition on ice while the heating in LIMA is distributed among depositions on ice, snow and graupel.

- The timing of the WCB ascents also differ between the two runs. While WCB ascents of LIMA occur in a rather small time window, those of ICE3 are more spread out during the run.

- The stronger WCB activity in ICE3 provides an explanation for the generally more rapid ridge building in ICE3 than LIMA, which is more obvious in the anticyclonic branch of the WCB outflow. In the cyclonic branch, the reverse happens in a rather localized region where the tropopause is more rapidly pushed outward in LIMA. This is due to more active fast ascents within localized convective cells north of the cold front resembling those studied by Oertel et al. (2019, 2021) and Blanchard et al. (2020, 2021).

The second part of the results was dedicated to the comparison with satellite observations and airborne observations collected during two flights of the SAFIRE Falcon-20 on 2 October 2016. The main results are as follows:

- The wind speed measured by the dropsondes during flight F6 at the leading edge of the ridge building resembles more that simulated by ICE3 than LIMA. Closer to the cyclone center, in situ airborne measurements and radar Doppler measurements of flight F7 also support the idea that ICE3 performs slightly better than LIMA in the representation of upperlevel circulation. 
- A comparison of the simulated brightness temperatures with the observed one from MSG shows that the cooler (or higher altitude) clouds found in ICE3 than LIMA are more realistic.

- The comparison between the simulated reflectivities computed with the radar forward operator of Borderies et al. (2018) and the observed reflectivity shows that (i) above $6 \mathrm{~km}$, the ICE3 reflectivity is higher than the LIMA one and closer to the observations, (ii) between 2 and $6 \mathrm{~km}$, both ICE3 and LIMA reflectivities largely underestimate the observed one, and (iii) below the melting layer, the observed reflectivity is slightly better represented by LIMA. When looking at the vertical distribution LIMA is more realistic but it more largely underestimates the observed reflectivity in the cold phase than ICE3.

- The comparison between the retrieved IWC computed with the DARDAR-CLOUD algorithm (Delanoë and Hogan 2008) and the model IWC confirms the reflectivity results. Above $6 \mathrm{~km}$, the ICE3 IWC is higher and closer to the retrieved IWC than to LIMA IWC. Between 2 and $6 \mathrm{~km}$, both simulations largely underestimate IWC by an average factor of 2-3 but the underestimation is more pronounced in LIMA. This result is consistent with the hydrometeors mass mixing ratio underestimation along the WCB with LIMA compared to ICE3.

Both the radar-to-model and model-to-radar approaches provide the same picture giving us confidence in the results: the cold hydrometeors are largely underestimated by the model and more importantly by LIMA.

The present study relies on the representation of a unique extratropical cyclone, which was a very deep cyclone triggered by synoptic-scale upper-level forcing and characterized by a very active warm conveyor belt. Dearden et al. (2016) stated that a strong dynamical forcing could overshadow microphysical sensitivities. This is the reason why similar simulations have been performed for a more moderate extratropical cyclone observed during IOP10 of NAWDEX (Schäfler et al. 2018; Sánchez et al. 2020; Steinfeld et al. 2020) that had a weaker synoptic forcing. This case, which is referred to as the Thor ridge case in Schäfler et al. (2018), led to more numerous WCB trajectories in ICE3 than LIMA (55\% more) that lead to a more rapidly amplified ridge building with ICE3 (not shown). Other sensitivity experiments have been made by changing the starting times of the simulations of the two cyclones and by using ECMWF datasets to initialize and force the model and this did not change the main picture provided in the present study. While the intensity of the PV anomaly may depend on the starting times and the domain extension, the previously mentioned tests provide confidence in the general character of our comparison between LIMA and ICE3.

The comparisons with observations emphasize the important issue of the large underestimation of the reflectivity and ice water content in the model. It has also been observed in all our sensitivity tests. Such an underestimation has also been noticed by Rysman et al. (2018) over the Mediterranean comparing the Weather and Research Forecasting Model to satellite and radar data over a 2 -yr period. They pointed out the need of providing more realistic frozen hydrometeor contents.
Our hypothesis is that it is the adjustment to saturation in cold and mixed phases that helps ICE3 to get more ice than LIMA. This leads to a better representation of the WCB and more accurate upper-level dynamics in the former than the latter run even though the adjustment to saturation has less physical meaning than an explicit vapor deposition. This importance of the adjustment to saturation is supported by some sensitivity tests that we have performed. In particular, as LIMA does not have a subgrid condensation scheme, we turned it off in ICE3 and this change had rather small effects in IWC, reflectivity and upper-level ridge even though nonnegligible. Two approaches can be envisaged in the future to get the model more realistic:

- In ICE3 and LIMA, one possibility will be to improve the representation of hydrometeors, especially by modifying the snow particle size distribution assumptions. In LIMA another possibility will be to test a new version including a twomoment description of snow and graupel. Impact of such changes should be on snow and graupel fall speeds and mass mixing ratios.

- In ICE3, different ways of determining the supersaturation distribution between liquid and solid will be tested in mixedphase cloud. Such choices might have an impact on latent heating release in middle troposphere as latent release is stronger for vapor to ice than vapor to liquid.

For operational purposes, it is important to more systematically compare ICE3 and LIMA to better characterize in which situations one scheme performs better than the other. Taufour et al. (2018) underlined the better behavior of LIMA in the representation of two convective precipitation events during HyMeX while the present study rather shows the reverse in a large-scale extratropical cyclone. More case studies would be needed to confirm these preliminary results.

Acknowledgments. We thank David Flack for proofreading an early version of the manuscript and correcting the English spelling and grammar. This work was funded by several projects: EARTHCARE RALI NAWDEX-EPATAN ESA Contract 4000119015/NL_CT/gp, CNES AEOLUS/EECLAT, F-NAWDEX of the French national programme INSU/LEFE, and ANR DIP-NAWDEX (ANR-17-CE01-0010).

Data availability statement. Data are available on request from the authors.

\section{REFERENCES}

Appenzeller, C., and J. R. Holton, 1997: Tracer lamination in the stratosphere: A global climatology. J. Geophys. Res., 102, 13 555-13 569, https://doi.org/10.1029/97JD00066.

Augros, C., O. Caumont, V. Ducrocq, N. Gaussiat, and P. Tabary, 2016: Comparisons between S-, C-and X-band polarimetric radar observations and convective-scale simulations of the HyMeX first special observing period. Quart. J. Roy. Meteor. Soc., 142, 347-362, https://doi.org/10.1002/qj.2572.

Avramov, A., and J. Y. Harrington, 2010: Influence of parameterized ice habit on simulated mixed phase arctic clouds. J. Geophys. Res., 115, D03205, https://doi.org/10.1029/2009JD012108.

Berman, J. D., and R. D. Torn, 2019: The impact of initial condition and warm conveyor belt forecast uncertainty on variability in 
the downstream waveguide in an ECWMF case study. Mon. Wea. Rev., 147, 4071-4089, https://doi.org/10.1175/MWR-D18-0333.1.

Binder, H., M. Boettcher, H. Joos, and H. Wernli, 2016: The role of warm conveyor belts for the intensification of extratropical cyclones in Northern Hemisphere winter. J. Atmos. Sci., 73, 3997-4020, https://doi.org/10.1175/JAS-D-15-0302.1.

Blanchard, N., F. Pantillon, J.-P. Chaboureau, and J. Delanoë, 2020: Organization of convective ascents in a warm conveyor belt. Wea. Climate Dyn., 1, 617-634, https://doi.org/10.5194/ wcd-1-617-2020.

$-, \ldots, \ldots$, and — 2021: Mid-level convection in a warm conveyor belt accelerates the jet stream. Wea. Climate Dyn., 2, 37-53, https://doi.org/10.5194/wcd-2-37-2021.

Blonsky, S., and P. Speth, 1998: An algorithm to detect tropopause folds from ozone soundings. Meteor. Z., 7, 153-162, https:// doi.org/10.1127/metz/7/1998/153.

Borderies, M., and Coauthors, 2018: Simulation of W-band radar reflectivity for model validation and data assimilation. Quart. J. Roy. Meteor. Soc., 144, 391-403, https://doi.org/10.1002/ qj.3210.

Bougeault, P., and P. Lacarrere, 1989: Parameterization of orographyinduced turbulence in a mesobeta-scale model. Mon. Wea. Rev., 117, 1872-1890, https://doi.org/10.1175/1520-0493(1989) 117<1872:POOITI > 2.0.CO;2.

Brogniez, G., C. Pietras, M. Legrand, P. Dubuisson, and M. Haeffelin, 2003: A high-accuracy multiwavelength radiometer for in situ measurements in the thermal infrared. Part II: Behavior in field experiments. J. Atmos. Oceanic Technol., 20, 1023-1033, https:// doi.org/10.1175/1520-0426(2003)20<1023:AHMRFI>2.0.CO;2.

Browning, K. A., 1986: Conceptual models of precipitation systems. Wea. Forecasting, 1, 23-41, https://doi.org/10.1175/15200434(1986)001<0023:CMOPS > 2.0.CO;2.

Caniaux, G., J. Redelsperger, and J. P. Lafore, 1994: A numerical study of the stratiform region of a fast-moving squall line. Part I: General description and water and heat budgets. J. Atmos. Sci., 51, 2046-2074, https://doi.org/10.1175/1520-0469(1994) $051<2046$ :ANSOTS $>2.0$. CO;2.

Caumont, O., and Coauthors, 2006: A radar simulator for highresolution nonhydrostatic models. J. Atmos. Oceanic Technol., 23, 1049-1067, https://doi.org/10.1175/JTECH1905.1.

Cazenave, Q., 2019: Development and evaluation of multisensor methods for EarthCare mission based on A-Train and airborne measurements. Thesis, Université Paris-Saclay, https:// tel.archives-ouvertes.fr/tel-02076316.

Chaboureau, J.-P., and P. Bechtold, 2002: A simple cloud parameterization derived from cloud resolving model data: Diagnostic and prognostic applications. J. Atmos. Sci., 59, 2362-2372, https://doi.org/10.1175/1520-0469(2002)059<2362:ASCPDF> 2.0.CO;2.

Cohard, J.-M., J.-P. Pinty, and C. Bedos, 1998: Extending Twomey's analytical estimate of nucleated cloud droplet concentrations from CCN spectra. J. Atmos. Sci., 55, 3348-3357, https://doi.org/ 10.1175/1520-0469(1998)055<3348:ETSAEO>2.0.CO;2.

Colella, P., and P. R. Woodward, 1984: The Piecewise Parabolic Method (PPM) for gas-dynamical simulations. J. Comput. Phys., 54, 174-201, https://doi.org/10.1016/0021-9991(84)90143-8.

Coronel, B., D. Ricard, G. Rivière, and P. Arbogast, 2015: Role of moist processes in the tracks of idealized midlatitude surface cyclones. J. Atmos. Sci., 72, 2979-2996, https://doi.org/10.1175/ JAS-D-14-0337.1.

Crezee, B., H. Joos, and H. Wernli, 2017: The microphysical building blocks of low-level potential vorticity anomalies in an idealized extratropical cyclone. J. Atmos. Sci., 74, 1403-1416, https://doi.org/10.1175/JAS-D-16-0260.1.

Cuxart, J., P. Bougeault, and J.-L. Redelsperger, 2000: A turbulence scheme allowing for mesoscale and large-eddy simulations. Quart. J. Roy. Meteor. Soc., 126, 1-30, https://doi.org/ 10.1002/qj.49712656202.

Davis, C. A., M. T. Stoelinga, and Y.-H. Kuo, 1993: The integrated effect of condensation in numerical simulations of extratropical cyclogenesis. Mon. Wea. Rev., 121, 2309-2330, https://doi.org/ 10.1175/1520-0493(1993)121<2309:TIEOCI>2.0.CO;2.

Dearden, C., G. Vaughan, T. Tsai, and J.-P. Chen, 2016: Exploring the diabatic role of ice microphysical processes in two North Atlantic summer cyclones. Mon. Wea. Rev., 144, 1249-1272, https://doi.org/10.1175/MWR-D-15-0253.1.

Delanoë, J., and R. J. Hogan, 2008: A variational scheme for retrieving ice cloud properties from combined radar, lidar, and infrared radiometer. J. Geophys. Res., 113, D07204, https:// doi.org/10.1029/2007JD009000.

_ A. Arotat, O. Jourdan, J. Pelon, M. Papazzoni, R. Dupuy, J.-F. Gayet, and C. Jouan, 2013: Comparison of airborne in situ, airborne radar-lidar, and spaceborne radar-lidar retrievals of polar ice cloud properties sampled during the POLARCAT campaign. J. Atmos. Oceanic Technol, , 30, 5773, https://doi.org/10.1175/JTECH-D-11-00200.1.

Dirren, S., M. Didone, and H. Davies, 2003: Diagnosis of "forecastanalysis" differences of a weather prediction system. Geophys. Res. Lett., 30, 2060, https://doi.org/10.1029/2003GL017986.

Ducrocq, V., and Coauthors, 2014: HyMeX-SOP1: The field campaign dedicated to heavy precipitation and flash flooding in the northwestern Mediterranean. Bull. Amer. Meteor. Soc., 95, 1083-1100, https://doi.org/10.1175/BAMS-D-12-00244.1.

Eckhardt, S., A. Stohl, H. Wernli, P. James, C. Forster, and N. Spichtinger, 2004: A 15-year climatology of warm conveyor belts. J. Climate, 17, 218-237, https://doi.org/10.1175/15200442(2004)017<0218:AYCOWC>2.0.CO;2.

Flack, D., G. Rivière, I. Musat, R. Roehrig, S. Bony, J. Delanoë, Q. Cazenave, and J. Pelon, 2021: Representation by two climate models of the dynamical and diabatic processes involved in the development of an explosively-deepening cyclone during NAWDEX. Wea. Climate Dyn., 2, 233-253, https://doi.org/ 10.5194/wcd-2-233-2021.

Forbes, R. M., and P. A. Clark, 2003: Sensitivity of extratropical cyclone mesoscale structure to the parametrization of ice microphysical processes. Quart. J. Roy. Meteor. Soc., 129, 11231148, https://doi.org/10.1256/qj.01.171.

Gehring, J., A. Oertel, É. Vignon, N. Jullien, N. Besic, and A. Berne, 2020: Microphysics and dynamics of snowfall associated with a warm conveyor belt over Korea. Atmos. Chem. Phys., 20, 73737392, https://doi.org/10.5194/acp-20-7373-2020.

Gettelman, A., and Coauthors, 2010: Global simulations of ice nucleation and ice supersaturation with an improved cloud scheme in the community atmosphere model. J. Geophys. Res., 115, D18216, https://doi.org/10.1029/2009JD013797.

Gheusi, F., and J. Stein, 2002: Lagrangian description of airflows using Eulerian passive tracers. Quart. J. Roy. Meteor. Soc., 128, 337-360, https://doi.org/10.1256/00359000260498914.

Gierens, K. M., M. Monier, and J.-F. Gayet, 2003: The deposition coefficient and its role for cirrus clouds. J. Geophys. Res., 108, 4069, https://doi.org/10.1029/2001JD001558.

Gray, S. L., C. Dunning, J. Methven, G. Masato, and J. M. Chagnon, 2014: Systematic model forecast error in Rossby wave structure. Geophys. Res. Lett., 41, 2979-2987, https:// doi.org/10.1002/2014GL059282. 
Grewe, V., and M. Dameris, 1996: Calculating the global mass exchange between stratosphere and troposphere. Ann. Geophys., 14, 431-442, https://doi.org/10.1007/s00585-996-0431-x.

Harrold, T., 1973: Mechanisms influencing the distribution of precipitation within baroclinic disturbances. Quart. J. Roy. Meteor. Soc., 99, 232-251, https://doi.org/10.1002/qj.49709942003.

Hashimoto, A., M. Murakami, T. Kato, and M. Nakamura, 2007: Evaluation of the influence of saturation adjustment with respect to ice on meso-scale model simulations for the case of 22 June, 2002. SOLA, 3, 85-88, https://doi.org/10.2151/ sola.2007-022.

Heymsfield, A. J., L. M. Miloshevich, C. Twohy, G. Sachse, and S. Oltmans, 1998: Upper-tropospheric relative humidity observations and implications for cirrus ice nucleation. Geophys. Res. Lett., 25, 1343-1346, https://doi.org/10.1029/98GL01089.

Hogan, R. J., L. Tian, P. R. Brown, C. D. Westbrook, A. J. Heymsfield, and J. D. Eastment, 2012: Radar scattering from ice aggregates using the horizontally aligned oblate spheroid approximation. J. Appl. Meteor. Climatol., 51, 655-671, https:// doi.org/10.1175/JAMC-D-11-074.1.

Holton, J., 2004: The general circulation. An Introduction to Dynamic Meteorology, J. Holton and G. Hakim, Eds., International Geophysics Series, Vol. 88, Academic Press, 313-369.

Hoskins, B. J., M. McIntyre, and A. W. Robertson, 1985: On the use and significance of isentropic potential vorticity maps. Quart. J. Roy. Meteor. Soc., 111, 877-946, https://doi.org/ 10.1002/qj.49711147002.

Joos, H., and H. Wernli, 2012: Influence of microphysical processes on the potential vorticity development in a warm conveyor belt: A case-study with the limited-area model COSMO. Quart. J. Roy. Meteor. Soc., 138, 407-418, https://doi.org/ 10.1002/qj.934.

_- and R. M. Forbes, 2016: Impact of different IFS microphysics on a warm conveyor belt and the downstream flow evolution. Quart. J. Roy. Meteor. Soc., 142, 2727-2739, https://doi.org/ 10.1002/qj.2863.

Kessler, E., 1969: On the Distribution and Continuity of Water Substance in Atmospheric Circulations. Amer. Meteor. Soc., $84 \mathrm{pp}$.

Khain, A., and Coauthors, 2015: Representation of microphysical processes in cloud-resolving models: Spectral (bin) microphysics versus bulk parameterization. Rev. Geophys., 53, 247322, https://doi.org/10.1002/2014RG000468.

Kuo, Y.-H., M. Shapiro, and E. G. Donall, 1991: The interaction between baroclinic and diabatic processes in a numerical simulation of a rapidly intensifying extratropical marine cyclone. Mon. Wea. Rev., 119, 368-384, https://doi.org/10.1175/ 1520-0493(1991)119<0368:TIBBAD>2.0.CO;2.

Lac, C., and Coauthors, 2018: Overview of the Méso-NH model version 5.4 and its applications. Geosci. Model Dev., 11, 19291969, https://doi.org/10.5194/gmd-11-1929-2018.

Maddison, J., S. Gray, O. Martinez-Alvarado, and K. Williams, 2019: Upstream cyclone influence on the predictability of block onsets over the Euro-Atlantic region. Mon. Wea. Rev., 147, 1277-1296, https://doi.org/10.1175/MWR-D-180226.1.

Madonna, E., H. Wernli, H. Joos, and O. Martius, 2014: Warm conveyor belts in the ERA-Interim dataset (1979-2010). Part I: Climatology and potential vorticity evolution. J. Climate, 27, 3-26, https://doi.org/10.1175/JCLI-D-12-00720.1.

Manabe, S., 1956: On the contribution of heat released by condensation to the change in pressure pattern. J. Meteor. Soc. Japan, 34, 308-320, https://doi.org/10.2151/jmsj1923.34.6_308.
Martínez-Alvarado, O., E. Madonna, S. L. Gray, and H. Joos, 2016: A route to systematic error in forecasts of Rossby waves. Quart. J. Roy. Meteor. Soc., 142, 196-210, https://doi.org/ 10.1002/qj.2645.

Meyers, M. P., P. J. DeMott, and W. R. Cotton, 1992: New primary ice-nucleation parameterizations in an explicit cloud model. J. Appl. Meteor., 31, 708-721, https://doi.org/10.1175/15200450(1992)031<0708:NPINPI >2.0.CO;2.

Mishchenko, M. I., L. D. Travis, and D. W. Mackowski, 1996: T-matrix computations of light scattering by nonspherical particles: A review. J. Quant. Spectrosc. Radiat. Transfer, 55, 535-575, https://doi.org/10.1016/0022-4073(96)00002-7.

Mlawer, E. J., S. J. Taubman, P. D. Brown, M. J. Iacono, and S. A. Clough, 1997: Radiative transfer for inhomogeneous atmospheres: RRTM, a validated correlated-k model for the longwave. J. Geophys. Res., 102, 16 663-16 682, https://doi.org/ 10.1029/97JD00237.

Morcrette, J.-J., 1991: Radiation and cloud radiative properties in the European Centre for Medium Range Weather Forecasts forecasting system. J. Geophys. Res., 96, 9121-9132, https:// doi.org/10.1029/89JD01597.

Oertel, A., M. Boettcher, H. Joos, M. Sprenger, H. Konow, M. Hagen, and H. Wernli, 2019: Convective activity in an extratropical cyclone and its warm conveyor belt-A casestudy combining observations and a convection-permitting model simulation. Quart. J. Roy. Meteor. Soc., 145, 1406-1426, https://doi.org/10.1002/qj.3500.

- M. Sprenger, H. Joos, M. Boettcher, H. Konow, M. Hagen, and H. Wernli, 2021: Observations and simulation of intense convection embedded in a warm conveyor belt-How ambient vertical wind shear determines the dynamical impact. Wea. Climate Dyn., 2, 89-110, https://doi.org/10.5194/wcd-2-89-2021.

Pergaud, J., V. Masson, S. Malardel, and F. Couvreux, 2009: A parameterization of dry thermals and shallow cumuli for mesoscale numerical weather prediction. Bound.-Layer Meteor., 132, 83-106, https://doi.org/10.1007/s10546-009-9388-0.

Phillips, V. T., P. J. DeMott, and C. Andronache, 2008: An empirical parameterization of heterogeneous ice nucleation for multiple chemical species of aerosol. J. Atmos. Sci., 65, 27572783, https://doi.org/10.1175/2007JAS2546.1.

,,,--- K. A. Pratt, K. A. Prather, R. Subramanian, and C. Twohy, 2013: Improvements to an empirical parameterization of heterogeneous ice nucleation and its comparison with observations. J. Atmos. Sci., 70, 378-409, https://doi.org/ 10.1175/JAS-D-12-080.1.

Pinty, J., and P. Jabouille, 1998: A mixed-phase cloud parameterization for use in mesoscale non-hydrostatic model: Simulations of a squall line and of orographic precipitations. Preprints, Conf. on Cloud Physics, Everett, WA, Amer. Meteor. Soc., 217-220.

Pomroy, H. R., and A. J. Thorpe, 2000: The evolution and dynamical role of reduced upper-tropospheric potential vorticity in intensive observing period one of FASTEX. Mon. Wea. Rev., 128, 1817-1834, https://doi.org/10.1175/1520-0493(2000) $128<1817$ :TEADRO $>2.0$. CO; 2 .

Rasp, S., T. Selz, and G. C. Craig, 2016: Convective and slantwise trajectory ascent in convection-permitting simulations of midlatitude cyclones. Mon. Wea. Rev., 144, 3961-3976, https:// doi.org/10.1175/MWR-D-16-0112.1.

Reisin, T., Z. Levin, and S. Tzivion, 1996: Rain production in convective clouds as simulated in an axisymmetric model with detailed microphysics. Part I: Description of the model. J. Atmos. Sci., 53, 497-519, https://doi.org/10.1175/15200469(1996)053<0497:RPICCA > 2.0.CO;2. 
Robertson, F., and P. Smith, 1983: The impact of model moist processes on the energetics of extratropical cyclones. Mon. Wea. Rev., 111, 723-744, https://doi.org/10.1175/ 1520-0493(1983)111<0723:TIOMMP > 2.0.CO;2.

Rossa, A., H. Wernli, and H. Davies, 2000: Growth and decay of an extra-tropical cyclone's PV-tower. Meteor. Atmos. Phys., 73, 139-156, https://doi.org/10.1007/s007030050070.

Rysman, J.-F., S. Berthou, C. Claud, P. Drobinski, J.-P. Chaboureau, and J. Delanoë, 2018: Potential of microwave observations for the evaluation of rainfall and convection in a regional climate model in the frame of HyMeX and MED-CORDEX. Climate Dyn., 51, 837-855, https://doi.org/10.1007/s00382016-3203-7.

Sánchez, C., J. Methven, S. Gray, and M. Cullen, 2020: Linking rapid forecast error growth to diabatic processes. Quart. J. Roy. Meteor. Soc., 146, 3548-3569, https://doi.org/10.1002/ qj.3861.

Saunders, R., and Coauthors, 2013: RTTOV-11 science and validation report. NWP SAF Tech. Rep. NWPSAF-MO-TV-032, 62 pp., https://www.nwpsaf.eu/site/download/documentation/ rtm/docs_rttov11/rttov11_svr.pdf.

Schäfler, A., and Coauthors, 2018: The North Atlantic waveguide and downstream impact experiment. Bull. Amer. Meteor. Soc., 99, 1607-1637, https://doi.org/10.1175/BAMS-D-17-0003.1.

Schmetz, J., P. Pili, S. Tjemkes, D. Just, J. Kerkmann, S. Rota, and A. Ratier, 2002: An introduction to Meteosat Second Generation
(MSG). Bull. Amer. Meteor. Soc., 83, 977-992, https://doi.org/ 10.1175/BAMS-83-7-Schmetz-2.

Seity, Y., P. Brousseau, S. Malardel, G. Hello, P. Bénard, F. Bouttier, C. Lac, and V. Masson, 2011: The AROMEFrance convective-scale operational model. Mon. Wea. Rev., 139, 976-991, https://doi.org/10.1175/2010MWR3425.1.

Steinfeld, D., M. Boettcher, R. Forbes, and S. Pfahl, 2020: The sensitivity of atmospheric blocking to changes in upstream latent heating-numerical experiments. Wea. Climate Dyn., 1, 405-426, https://doi.org/10.5194/wcd-1-405-2020.

Taufour, M., and Coauthors, 2018: Evaluation of the two-moment scheme LIMA based on microphysical observations from the HyMeX campaign. Quart. J. Roy. Meteor. Soc., 144, 13981414, https://doi.org/10.1002/qj.3283.

Tompkins, A. M., K. Gierens, and G. Rädel, 2007: Ice supersaturation in the ECMWF integrated forecast system. Quart. J. Roy. Meteor. Soc., 133, 53-63, https://doi.org/10.1002/qj.14.

Vié, B., J.-P. Pinty, S. Berthet, and M. Leriche, 2016: LIMA (v1.0): A quasi two-moment microphysical scheme driven by a multimodal population of cloud condensation and ice freezing nuclei. Geosci. Model Dev., 9, 567-586, https://doi.org/10.5194/ gmd-9-567-2016.

Wernli, B. H., and H. C. Davies, 1997: A Lagrangian-based analysis of extratropical cyclones. I: The method and some applications. Quart. J. Roy. Meteor. Soc., 123, 467-489, https://doi.org/ 10.1002/qj.49712353811. 